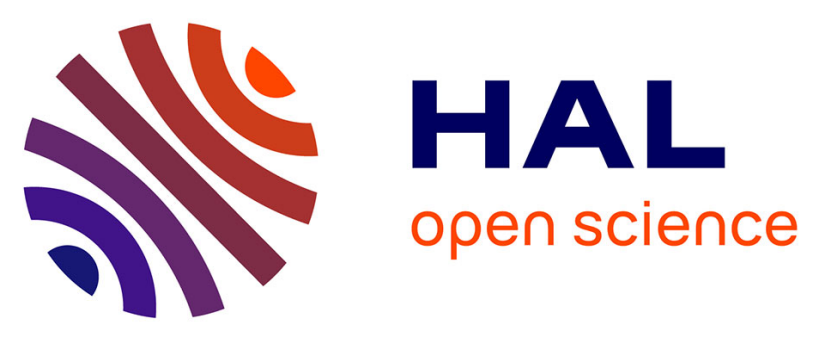

\title{
The skeletal remains of the euryhaline sclerorhynchoid $\dagger$ Onchopristis (Elasmobranchii) from the 'Mid'-Cretaceous and their palaeontological implications
}

Eduardo Villalobos-Segura, Jürgen Kriwet, Romain Vullo, Sebastian Stumpf, David J Ward, Charlie J Underwood

\section{To cite this version:}

Eduardo Villalobos-Segura, Jürgen Kriwet, Romain Vullo, Sebastian Stumpf, David J Ward, et al.. The skeletal remains of the euryhaline sclerorhynchoid †Onchopristis (Elasmobranchii) from the 'Mid'Cretaceous and their palaeontological implications. Zoological Journal of the Linnean Society, 2021, 193 (2), pp.746-771. 10.1093/zoolinnean/zlaa166 . insu-03134850

\section{HAL Id: insu-03134850 \\ https://hal-insu.archives-ouvertes.fr/insu-03134850}

Submitted on 8 Feb 2021

HAL is a multi-disciplinary open access archive for the deposit and dissemination of scientific research documents, whether they are published or not. The documents may come from teaching and research institutions in France or abroad, or from public or private research centers.
L'archive ouverte pluridisciplinaire $\mathbf{H A L}$, est destinée au dépôt et à la diffusion de documents scientifiques de niveau recherche, publiés ou non, émanant des établissements d'enseignement et de recherche français ou étrangers, des laboratoires publics ou privés. 
1 The skeletal remains of the euryhaline sclerorhynchoid $\dagger$ Onchopristis (Elasmobranchii,

4 by Eduardo Villalobos-Segura ${ }^{1}$, Jürgen Kriwet ${ }^{2}$, Romain Vullo ${ }^{3}$, Sebastian Stumpf ${ }^{2}$, David J.

5 Ward $^{4}$ and Charlie J. Underwood ${ }^{1}$.

$6{ }^{1}$ School of Earth Sciences, Birkbeck College, Malet Street, London, WC1E 7HX, UK

$7 \quad{ }^{2}$ University of Vienna, Department of Palaeontology, Geozentrum, Althanstraße 14, 1090

8 Vienna, Austria.

$9{ }^{3}$ UMR CNRS 6118 Géosciences, Université Rennes 1, Campus de Beaulieu263 avenue du 10 Général Leclerc, 35042 Rennes, France.

$11{ }^{4}$ Department of Earth Sciences, The Natural History Museum, London SW7 5BD, UK;

12

13

14 Running head: Skeletal remains of $\dagger$ Onchopristis

15 Corresponding author: Eduardo Villalobos-Segura, elasmo177@gmail.com 
27 Abstract. We present the first known cranial remains of the fossil batoid $\dagger$ Onchopristis numidus. Based on two exceptionally well preserved specimens collected from the "Kem Kem Beds" (Albian-Cenomanian), South-East of Morocco, an almost complete description of the rostral and cranial portions of the genus †Onchopristis is provided, together with new observations regarding the development and arrangement of the rostral denticle series for this genus. The comparison between the rostrum length of the specimens of $\dagger$ Onchopristis numidus with those of extant pristids revealed a relatively large batoid species with an estimated total length between two to four meters. Overall, the cranial morphology of $\dagger$ Onchopristis resembles that of other sclerorhynchoids. Its robust hypertrophied rostrum with the characteristic wood-like mineralisation covering the inner layer of tessellate cartilage at the centre of the rostrum, in addition to the thick lateral layers of densely porous cartilage on the sides of the rostral cartilages, resembles that observed in $\dagger$ Ischyrhiza and $\dagger$ Shizorhiza, and differentiates $\quad$ Onchopristis from other sclerorhynchoid (e.g. $\quad$ Micropristis, $\dagger$ Sclerorhynchus and $\uparrow$ Libanopristis). Aiming to determinate a phylogenetic relations of $\dagger$ Onchopristis within sclerorhynchoids a cladistic analysis carried out based on the remains described here, its results suggest a new taxonomic arrangement within sclerorhynchoids.

\section{INTRODUCTION}

†Onchopristis Stromer, 1917 is a puzzling Cretaceous batoid taxon, with most of its fossil record being recorded from many 'mid' Cretaceous sites in coastal and fluvial settings. The taxon was first described based only on rostral fragments and denticles (Haug, 1905; Stromer, 1917; 1925) (Fig. 1) with the teeth being described as $†$ Squatina aegyptiaca by Stromer (1927), but later assigned to $\dagger$ Onchopristis by Slaughter \& Thurmond (1974) (see also 
with $\dagger$ Onchopristis numidus erroneously to a new taxon, $\uparrow$ Sechmetia aegyptiaca. Currently, $\dagger$ Onchopristis is placed systematically in the suborder $\uparrow$ Sclerorhynchoidei within the family $\dagger$ Sclerorhynchidae (Cappetta, 2012), although this affiliation has not been tested phylogenetically.

57

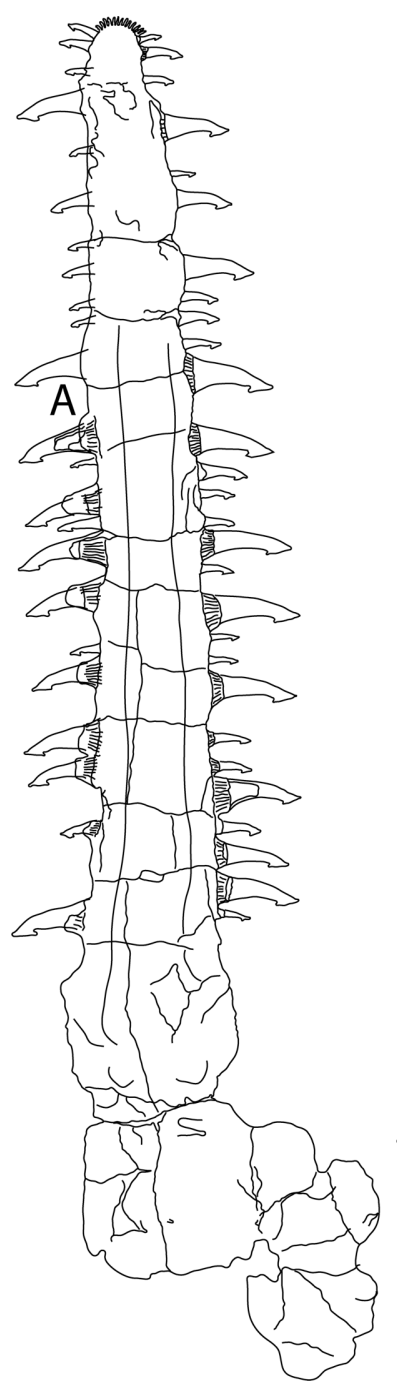

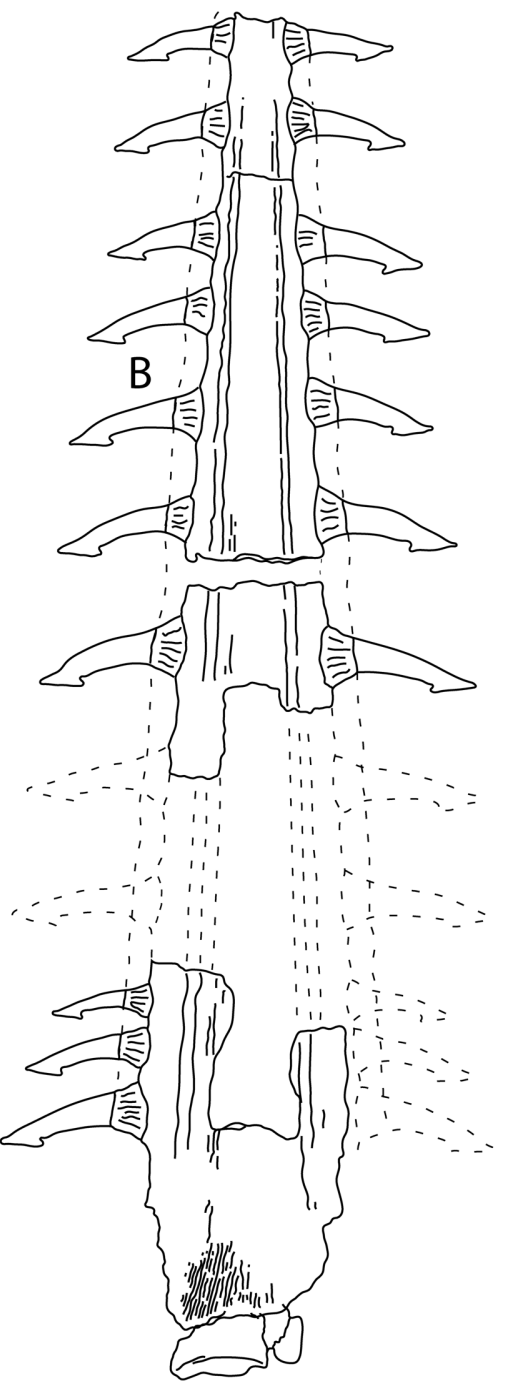

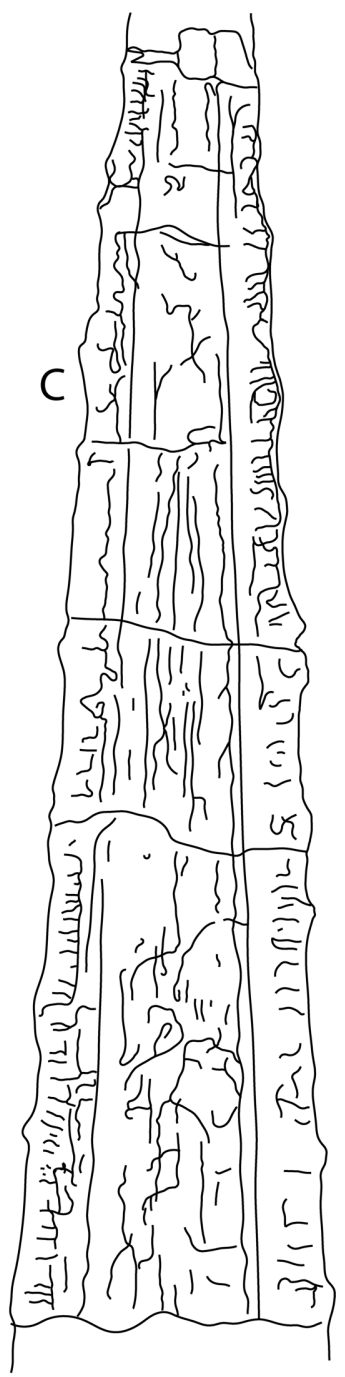

58 Figure 1. A. Rostral remains figured in Stromer (1925; TL $1450 \mathrm{~mm}$ ). B-C. Rostral remains figured in Stromer (1917; B, TL. 260 mm. C, TL. $520 \mathrm{~mm}$ ). The genus is restricted to the Barremian-Cenomanian (Kriwet, 1999) and presently 61 includes only two valid species (†Onchopristis numidus and $\dagger$ O. dunklei, see Table 1). $62 \dagger$ Onchopristis numidus (Haug, 1905) occurs in the Albian of Djoua, Algeria (Cappetta, 1987), 63 the Cenomanian of Egypt (Stromer, 1927; Slaughter \& Thurmond, 1974; Werner, 1989), the 
Albian-Cenomanian of Morocco (Cappetta, 1980). It should, however, be noted that the exact stratigraphic age of many of the North African sites is still in debate.

$\dagger$ Onchopristis dunklei (McNulty \& Slaughter, 1962) is reported from the Cenomanian and middle-upper Albian of Texas. However, the specimens collected from the Lower Cretaceous (Aptian-Albian), Trinity Group of Texas, U.S.A. are considered a subspecies by Thurmond (1971), who introduced the name $\uparrow$ Onchopristis dunklei/praecursor. $\dagger$ Onchopristis dunklei is also reported from the Albian of Tunisia, although this record is based on incomplete material (Cuny et al., 2004), and from the Cenomanian of Spain and France (Bernardez, 2002; Vullo et al., 2003; Néraudeau et al., 2005). In addition, an unnamed older species exists, which was recovered from Barremian deposits of north-eastern Spain (Kriwet, 1999).

$\dagger$ Onchopristis dunklei/praecursor also occurs in the Upper Cretaceous (CampanianMaastrichtian) of New Zealand by Keyes (1977). Martill \& Ibrahim (2012) revised this taxon and redescribed it as $\uparrow$ Australopristis wiffeni. Based on the differences between the specimens figured by Keyes (1977) and the teeth of typical †Onchopristis, Cappetta (2012) proposed that the sclerorhynchid rostral teeth from New Zealand might be close to $†$ Sclerorhynchus and might have acquired convergently morphologies with posterior barbs resembling that of $\uparrow$ Onchopristis. Alternatively, $\uparrow$ Australopristis maybe a sawshark belonging to Pristiophoridae, similar to $\uparrow$ Pliotrema.

Table 1. List of species assigned to $†$ Onchopristis with their currently accepted taxonomic status.

\begin{tabular}{|c|c|c|}
\hline Type of remains & Original description & Current taxonomic status \\
\hline \hline Oral & $\dagger$ Squatina aegyptiaca Stromer, 1927 & Syn. $\dagger$ O. numidus (Cappetta, 2006) \\
\hline Oral & $\dagger$ Sechmetia cruciformis Werner, 1989 & Syn. $\dagger$ O. dunklei (Cappetta, 2006) \\
\hline Oral & $\dagger$ Sechmetia aegyptiaca Stromer, 1927 & Syn. $\dagger$ O. numidus \\
\hline Oral and Rostral & $\dagger$ O. dunklei McNulty \& Slaughter, 1962 & Valid (Cappetta, 2006) \\
\hline Vertebra & $\dagger$ Platyspondylus foureaui Haug, 1905 & Syn. $\dagger$ O. numidus (Cappetta, 2006) \\
\hline Oral, Rostral and Cranial & $\dagger$ O. numidus (Haug, 1905) & Valid (Cappetta, 2006) \\
\hline Rostral & $\dagger$ Onchopristis sp. Werner, 1989 & Unknown species \\
\hline
\end{tabular}


The genus $\uparrow$ Onchopristis can be differentiated from other sclerorhynchoids in the shape and size of its rostral denticles (reaching $7 \mathrm{~cm}$ in length). The presence of barbs (hook-like protuberances directed backwards) situated on the posterior margin, along with numerous rectilinear folds along the posterior and anterior margins of the rostral denticles, are key features for their identification. Currently, the two valid species of $\dagger$ Onchopristis are differentiated from each other by the number of barbs associated with their rostral denticles: one in $\dagger$ O. numidus and several in $\dagger$. dunklei (Cappetta, 2012). Numerous hypotheses have been proposed to explain the development of this feature. Slaughter \& Steiner (1968) suggested that there is an evolutionary tendency to increase the number of barbs associated with the rostral denticles. However, a secondary loss cannot be discarded (i.e. the plesiomorphic state could be additional (more than one) barbs associated with the rostral denticles). McNulty \& Slaughter (1962) proposed that the number of barbs is related to the size of the rostral denticles, and as the denticles grow the number of barbs also increases. The presence of multiple barbed denticles (usually two) in specimens from Morocco and Egypt (Stromer, 1917, plate 1; Martill \& Ibrahim, 2012, text-fig. 3A-B and 5) (Fig. 7B) renders the use of the barb numbers as a valid character for species determination within $\dagger$ Onchopristis problematic. Despite this, the presence of multiple barbs is typical for North American specimens of $\uparrow O$. dunklei, but it is a rare feature observed in North African specimens assigned to $\dagger$ O. numidus, where these denticles comprise less than $1 \%$ of the rostral denticles.

Here, we describe previously unknown features for $\uparrow$ Onchopristis numidus based on several specimens recently collected from the "Kem Kem Beds" (Albian-Cenomanian) of SE Morocco and analysed their characters with those described for $\uparrow O$. dunklei. The new "Kem Kem" material reveals a peculiar arrangement of the enlarged lateral rostral denticle series with intercalations of various sizes, as well as the morphology of the synarcual and other cranial remains of the genus $\dagger$ Onchopristis for the first time. 
113 extensive non-marine succession of fluvial and fluvial-deltaic facies of Late Jurassic to

114 'middle' Cretaceous age (Kilian, 1931; De Lapparent, 1960; Cavin et al., 2010; Ibrahim et al., 115 2020). In Morocco, the 'Continental Intercalaire' is informally known as the "Kem Kem Beds"

116 (Sereno et al., 1996); this term subsequently was later restricted to deposits of mid-Cretaceous 117 age Albian and/or Cenomanian age (Cavin et al., 2010). The fluvial sandstone-dominated

118 facies contain an abundant and diverse vertebrate fauna and are the source of extensive small-

119 scale commercial fossil mining operations. The known fauna is dominated by diverse aquatic 120 and semi-aquatic taxa, with facultatively terrestrial forms being rare. These faunas have been 121 the subject of several studies (e.g. Dutheil, 1999; Cavin \& Forey, 2004; Rage \& Dutheil, 2008;

122 Belverde et al., 2013; Mannion \& Barret, 2013; Ibrahim et al., 2020).

The "Kem Kem Beds" are present along an escarpment at the north-eastern, eastern and

124 south-eastern margins of the Moroccan Anti-Atlas, and are underlain by folded Palaeozoic rocks and overlain by Cretaceous marine limestones that also form the top of the escarpments. This unit is typically divided into two units: the sandstone-dominated Ifezouane and the overlying mudstone-dominated Aoufous formations (Cavin et al., 2010; Ettachfini \& Andreu, 2004). Most vertebrate fossils from the southern part of the area come from the Ifezouane

129 Formation. In the northern part of the area, close to the mouth of the River Ziz gorge, well 130 preserved fish fossils, and amphibian and squamate remains are known from the Aoufous 131 Formation (Dutheil, 1999). Within the Ifezouane Formation, there is no formalised internal 132 stratigraphy, and there is no stratigraphic control on the fossil assemblages. Consequently, it is unknown whether the faunas found in the region have the same time

134 age or are an assemblage of multiple ages. Despite this lack of stratigraphic detail, the 
135 Ifezouane Formation in the South of the area rests unconformably on the basement and

136 comprises two channelised sandstone units separated by a major channel base surface. Most

137 fossils are known from the channel lag at the base of the upper unit. In the North, there are two

138 channelised sandstones separated by a heterolithic unit of siltstones and rippled sandstones. A

139 gypsum rich mudstone separates these sandstones from the basement below. Fossils are

140 common in both the channelised sandstones and the heterolithic unit, with the specimens

141 described here being collected from the heterolithic unit.

142 The majority of the publications describing fossils from the "Kem Kem Beds" utilise

143 commercially collected material with relatively few publications dealing with material

144 collected in situ (Dutheil, 1999, Rage \& Dutheil, 2008). As a result, palaeoecology studies of

145 the unit are biased by collection procedures (e.g. higher value specimens) and taphonomic

146 aspects (e.g. merging of stratigraphically, environmentally and geographically isolated faunas).

147 Some studies have assumed a rather homogeneous palaeoenvironment (Cavin et al., 2010) or

148 noted some stratigraphical variation in the faunas but did not link that to palaeoenvironments

149 (Läng et al., 2013). There is a general dominance of small remains (vertebrae, teeth and scales

150 fish) of actinopterygian fishes at all field sites, although these are of low commercial value and

151 small size and hence are underrepresented in many collections. Lungfish toothplates and

152 remains of coelacanths are found more irregularly. Chondrichthyan remains are common and

153 composed mainly of $\dagger$ Onchopristis numidus rostral denticles, along with vertebral centra and

154 fragments of rostral cartilages. †Onchopristis numidus teeth and smaller denticles are also

155 common but typically only are recovered by screen-washing due to their small size. Hybodont

156 fin spines are frequent macroscopic finds, with small hybodont teeth of several genera being

157 abundant in many sieved samples.

158 Lamniform and other elasmobranch shark teeth are present but rare. Tetrapod bone

159 fragments are also prevalent (especially chelonian carapace fragments, crocodilian bone 
160 fragments and spinosaurid teeth) and a vast diversity of large and small tetrapods are known.

161 Non-vertebrate remains include multiple gastropod species, small bivalves and carapace

162 fragments of decapod crustaceans, which are rarely recorded. Ferruginised pieces of wood

163 occur in some localities, especially in northern localities of the channel sandstone facies (e.g.

164 Aghanbou). These fossil assemblages and the sedimentology suggest a fluvial association, with

165 little evidence of marine influences. However, the frequent presence of $\dagger$ Onchopristis

166 numidus (present within coastal and brackish water facies in Egypt) may suggest a link to

167 coastal facies within which it is known elsewhere (Werner, 1989), and the occurrence of several

168 species of lamniform sharks (typically considered as marine) may suggest a direct and possibly

169 close connection to the marine environments.

170 The channel structures within the fluvial facies in some localities (e.g. Boufaddouz) are

171 immense, suggesting a considerable extension of the channels, which might have been part of

172 a meandering river system, as very large and sinuous channels persist in both Morocco and

173 Libya, indicating the continuity of an extensive river system.

\section{MATERIAL}

All specimens described here were obtained from Morocco-based commercial sources, with one of them (NHMUK PV P 75502) brought directly at the site of Boufza (UTM Easting 353973, UTM Northing 3509602, Zone 30), which facies are not exploited (i.e. commercially used) elsewhere (pers. observ. C. Underwood). Specimen IPUW 353500 presents an almost complete rostrum and an almost complete neurocranium, with only the left nasal cavity, hyomandibula, and some jaw elements missing. Specimen IGR 2818 shows an almost complete

182 rostrum with only the tip and the complete left side of the rostrum missing. The specimens NHMUK PV P 75502 and 75503 are rostral fragments. Additional small specimens of isolated teeth and denticles were largely collected in situ, typically from the weathered spoil of 
commercial excavations and by sieving of sediment gathered near those sites (e.g. Begaa (KK3): UTM Easting 418421, UTM Northing 3418555, Zone 30 and Boufaddouz (KK7): UTM Easting 373009, UTM Northing 3501097, Zone 30).

\section{Institutional abbreviations}

IGR: Geological Institute of the University of Rennes 1, NHMUK: Natural History Museum United Kingdom. IPUW: Palaeontological Collections of the University of Vienna Fossil material $\dagger$ Asflapristis cristadentis (NHMUK PV P 73925, 75428 a-e, 75429 a-d, 75431, 75432, 75433). $†$ Ischyrhiza mira (Sternes \& Shimada, 2019; text-fig. 2 a-I, text-fig. 4 a-f, text-fig 5 aI; Slaughter \& Steiner 1968; text-fig. 4A-C). † Micropristis solomonis (Cappetta, 1980, pl. 1, fig. 1-4; pl. 2, fig. 1). †Libanopristis hiram (Cappetta, 1980, pl. 1, fig. 4; NHMUK PV P 108705, 108706, 13858, 63610, 75075). †Onchopristis numidus (NHMUK PV P 75502, 75503, 1, 74045, 74047, 74050, 74051, 74052, 74053, 74054; IPUW 353500; IGR 2818, 2819, 2820, 2821). †Ptychotrygon rostrispatula (NHMUK PV P 73630, 75496, 75496, 75497, 75500). †Sclerorhynchus atavus (Slaughter \& Steiner, 1968, text-fig. 4D; NHMUK PV P 4017, 4776, 49546, 49518, 49533, 49547). †Shizorhiza stromeri (Smith et al., 2015; text-fig. 1a-1; 2a-f; NHMUK PV P 73625). †Spathobatis bugesicus (NHMUK PV P 6010, 2099 (2); BSP AS I 505, 1952 I 82).

\section{Abbreviations used in the figures}

Ac, antorbital cartilage; Alp, anterior lateral process; Bpc, buccopharyngeal nerve cavity; Bre, branchial elements; Cc, corpus calcareum; Cdb, cyclical deposition bar; Den, dermal denticle; Ed, enlarged denticle; Enm, enameloid; Hym, hyomandibula; I, Intermedialia; Ja, jugal arch; Lc, lateral commissure; Lf, lymphatic foramina; Ll, laminar layer, Ls, lateral stays; Mc, medial crest; Mkc, Meckel's cartilage; Oc, occipital condyle; OdP, odontoid process; Of, orbital foramen; Op, optic pedicel; Orb, orbital cavity; Ort, orthodentine; Ost, 
osteodentine; Pcf, precerebral fenestra; Pop, postorbital process; Pq, palatoquadrate; PrCar,

211 periphery cartilage; Rd, rostral denticle; Sof, spino-ochipital foramina; Sophc, supra

212 ophthalmic nerve cavity; VII, hyomandibular branch of the facial nerve foramen; Wc, Wood-

213 like cartilage.

Smaller specimens were field-collected from several sites along the main Kem Kem escarpment. Despite the extensive outcrops, exposures are restricted, and fossiliferous sites are commercially exploited. Spoil is exposed to wind ablation and (rare) rain exposing fossils therein allowing the surface collection of larger specimens and enabling dry sieving through 0.5 or $1 \mathrm{~mm}$ mesh sieves to collect small specimens. Sieved residues were later additionally wet sieved and picked under a microscope.

Mechanical preparation was carried out in all larger specimens to remove sediment and reveal features concealed by it, for the smaller disarticulated specimens the lab work involved the sagittal and axial cutting and polishing of rostral denticles in order to check their internal morphological features.

Further histology patterns of isolated rostral denticles and teeth were examined at the Department of Palaeontology of the University of Vienna using a desktop micro-computed tomography (micro-CT) device (Bruker SkyScan 1173). The software packages DataViewer (Bruker, version 1.5.1.2) and Amira (FEI Visualization, version 5.4.g) to generate 3D volume renderings of the generated micro-CT slice file stacks from the fossil material and to digitally dissect it using clipping planes of different angles.

To determinate the phylogenetic implications of these newly discovered remains of

$233 \dagger$ Onchopristis and to test their phylogenetic relations within sclerorhynchoids, a matrix of 14 taxa and 29 characters based on previous works (Aschliman et al., 2012; Claeson et al., 2013; 
Underwood \& Claeson, 2017; Villalobos et al., 2019a; b) with modifications to account for the morphological variation added by the specimens described here was assembled in Mesquite 3.31 (Maddison \& Maddison, 2018) (Supplementary materials) and analysed. As batoids monophyly is well-established by molecular and morphological analyses (e.g. Douady et al., 2003; Naylor et al., 2012 McEachran \& Aschliman, 2004; Aschliman et al., 2012), and not being the objective of the present study to test this, the selection of the outgroups included only batoids. To properly test the affiliation of $\dagger$ Onchopristis within sclerorhynchoids and the monophyly of sclerorhynchoids, the outgroup was composed by taxa that have been previously found in a sister relation to sclerorhynchoids by other phylogenetic analyses (e.g. Pristis by

244 Kriwet, 2004 and Underwood \& Claeson, 2017, Spathobatis by Claeson et al., 2013, and rajoids (Raja and Bathyraja) by Villalobos et al., 2019a; b). It is worth mention that the proximity of these taxa to sclerorhynchoids variates depending on the analysis (i.e. they are not

247 always in immediate proximity to sclerorhynchoids). The outgroup also included Anoxypristis to contain all Pristidae genera (Fricke et al., 2020), and Rhinobatos a genus that no previous analysis has placed in proximity to sclerorhynchoids, but present similarities with the other outgroup taxa in the analysis.

As the specimens described here are mostly composed of rostral and neurocranium remains, the selection of character was focused heavily on these structures, trying to avoid the uncertainty associated with the extensive inclusion of missing data. However, some postcranial skeletal features like the enlargement and shape of the proximal pectoral elements were kept

255 (Char. 1, see supporting information for character discussion), as they provide key features that distinguish sclerorhynchoids from other batoids. For the comparison of the specimens described here, eight sclerorhynchoid genera from which skeletal remains are known are included and compose the ingroup in the analysis. Some tooth features were used, although not extensively, because they would involve further preparation and possible damage to the 
specimens within the museums. Contingent or reductive coding (Brazeau, 2011) was used as

261 the coding method. Finally, the matrix was analysed using the recently published algorithm of

262 Brazeau et al., (2019) in the R package TreeSearch and compared with the tree resulted from

263 a heuristic search using TNT 1.5 (Goloboff et al., 2013).

For the TNT analysis, the command line was used to perform a heuristic search with unweighted characters, which included TBR (tree bisection and reconnection) as search algorithm and stepwise addition of 1000 random replications (see, supplementary material). While for the TreeSearch analysis a script available at "https://cran.rproject.org/web/packages/TreeSearch/vignettes/inapplicable.html', was followed (see supplementary material for the R script). The clade support was estimated using Jackknife analysis with 1000 iterations was performed in TreeSearch supplementary the group support was also estimated for the TNT analysis using frequency differences (Goloboff et al., 2013). Two uninformative characters (Chars. 3 and 11) were kept in the analyses, and although they do not provide grouping information, they were map in the resulting phylogenetic tree as they

274 offer interesting discussion points. All character optimisations were mapped on 275 TreeSearch and discussed in the Supplementary material.

RESULTS

BATOMORPHII Cappetta, 1980

RAJIFORMES SENSU Naylor et al., 2012

†SCLERORHYNCHOIDEI Cappetta, 1980 
Type species: †Onchopristis numidus (Haug, 1905)

DESCRIPTION

†ONCHOPRISTIS NUMIDUS (Haug, 1905)

(Figs. 2-15)

\section{Diagnosis}

Sclerorhynchoids of relatively large size $(\mathrm{TL} \sim 4 \mathrm{~m})$. Rostrum massive and with reinforcements having a triangular shapes. Rostrum consists of tessellated cartilage formed by a layer of small of prismatic ( tessellate or mosaic-like) calcified cartilage blocks covered by a layer of fibrous cartilage similar to wood cortex with several vertical, parallel and well mineralised ridges (i.e. 'wood-like' cartilage layer), along the central part of the rostrum and covering the grooves of the ophthalmic nerves. The periphery of the rostrum presents a thick layer of porous cartilage, where enlarge lateral series of rostral denticles attach. Rostral denticles on the lateral series of the rostrum are slender their caps are larger than the peduncle and its apical posterior region present hook-like projections (barbs). The number of barbs varies for 1-3 (one being the most common). The posterior surface of the enlarged rostral denticles presents several well marked ridges $(\sim 11)$ extending from the base and converging at the base of the barb. The denticles anterior face ornamented with smaller ridges that reach the lower third of the cap. The basal bulge is well marked. The peduncle is small with flat and strongly grooved lateral faces. The denticles on the lateral cephalic series do not present barbs and are smaller and wider than the rostrum series and do not present a pulp cavity. Lateral rostral denticles with a large pulp cavity at their base that becomes extremely narrow almost undetectable at the cap. Tooth crown with a large medial cusp and laterally expanded by the lateral shoulders (cusplets). The acute cusp is triangular-shaped bent lingually. On lateral view the labial profile is convex, and the long apron projects anteriorly surpassing the root. The 
311 lingual profile is concave with an almost incipient uvula. The root is more prominent than the

312 crown and protrudes laterally, and its vascularisation is holaulacorhize. Large denticles with

313 an enameloid crest on the anterior surface are associated with the body.

314 Differential diagnosis: Rostral denticles of $\dagger$ Onchopristis numidus have an orthodentine

315 filled cap, with a smaller pulp cavity that extends into the denticle cap, whereas the rostral

316 denticles of $\uparrow O$. dunklei possess a larger pulp cavity that extends well into the denticle cap with

317 a thin orthodentine layer.

318

319 Temporal and spatial distribution

320 Albian- Cenomanian of Africa (Egypt by Werner, 1989: plate 19-20, 23, 35-38) and

321 Morocco by Cappetta (1980) and the present study).

322

323 Etymology

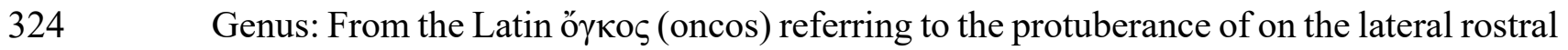

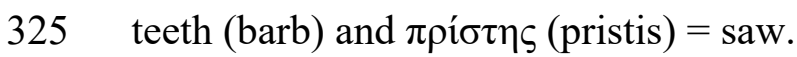

326 Species: From Numidia the old kingdom bereber, that comprehended (Algeria and part 327 of Tunisia) 


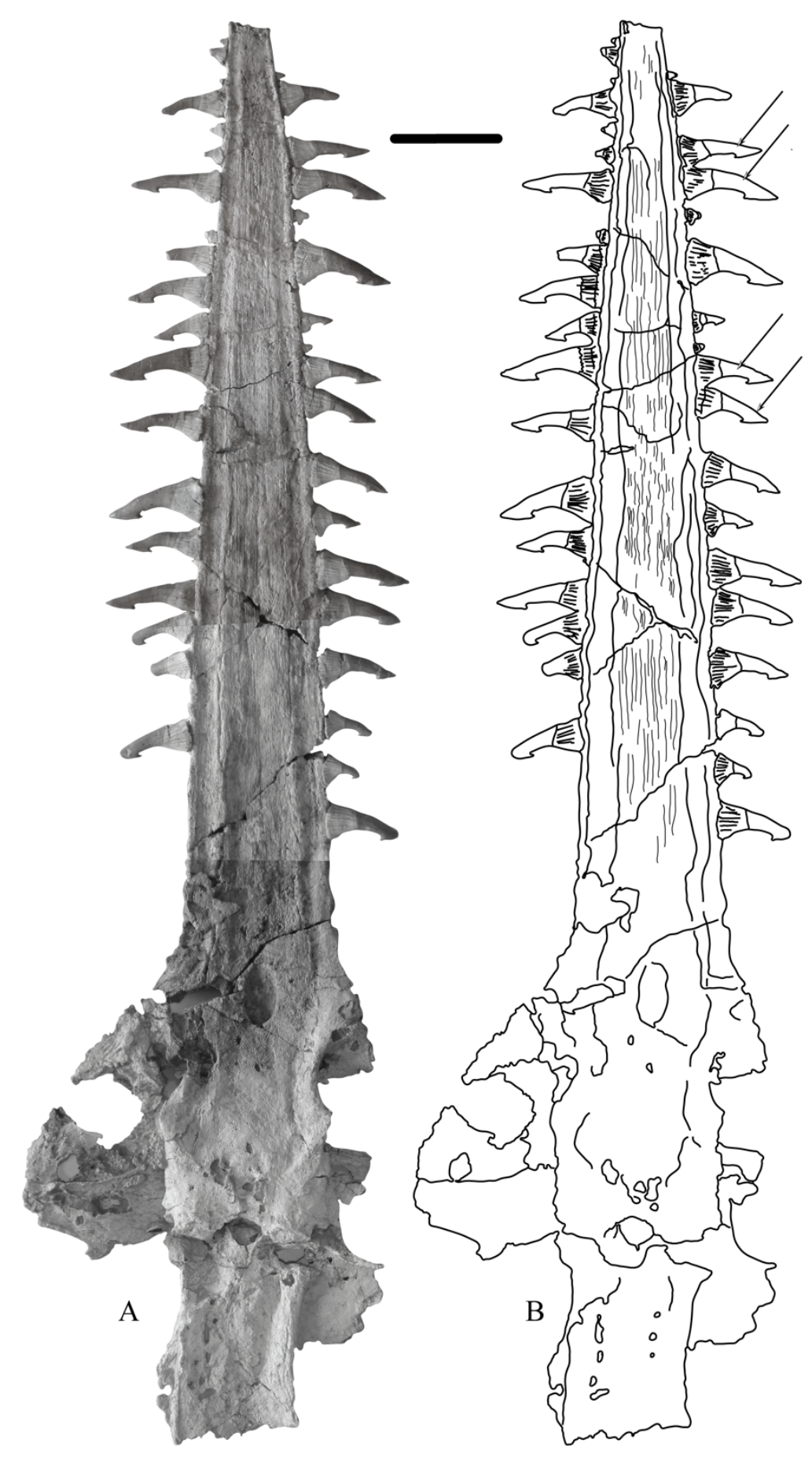

329 Figure 2. A, Cranial and rostral remains of †Onchopristis numidus (IPUW 353500). B,

330 Interpretative line drawing of the specimen remains. Denticles in pair arrangement marked with 331 an arrow. Scale bar: $5 \mathrm{~cm}$. 


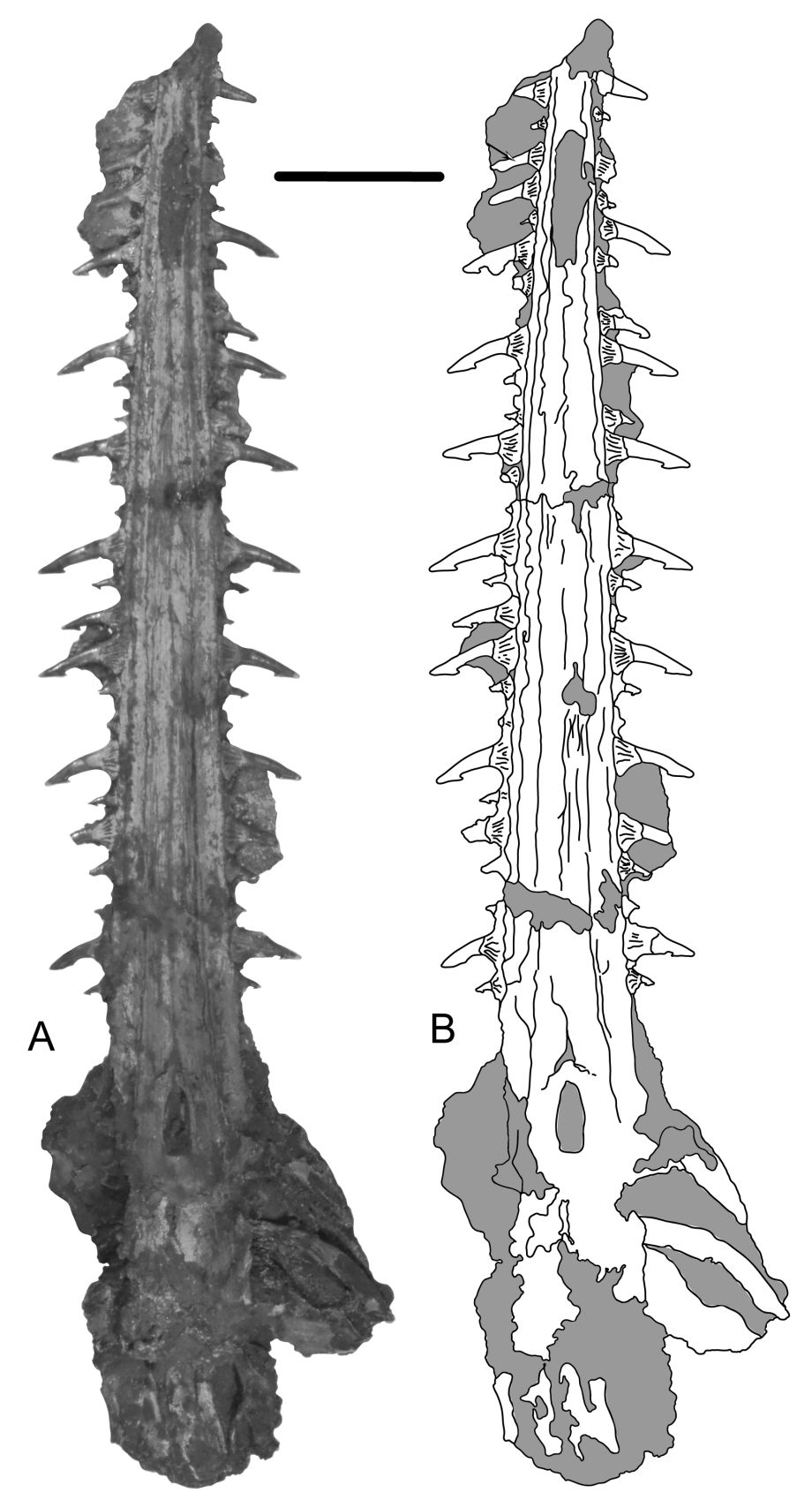

333 Figure 3. A, Cranial and rostral remains of $\uparrow$ Onchopristis numidus (IGR 2818). B, line

334 drawing of the specimen remains (darken areas represent rock matrix). Denticles in pair 335 arrangement marked with an arrow. Scale bar: $10 \mathrm{~cm}$. The hypertrophied rostrum is robust and triangular-shaped, reaching its widest point at the base and narrowing towards the tip (length: width at base ratio 0.0186) (Figs. 2-3). The 
base of the rostrum progresses smoothly into the neurocranium. After removal of the sediment,

341 the specimens revealed the presence of a layer of 'wood-like' cartilage layer, covering the inner

342 tessellate (mosaic-like) cartilage along the central part of the rostrum. This layer was first

343 observed in $†$ Onchopristis by Stromer (1917) and characterised as possible fossilised skin.

344 Later it was described by Cappetta (1980) as the cartilage covering the canals for the ophthalmic nerves in the rostrum. Sternes \& Shimada (2019; fig. 2c) describe a similar cartilage type located at the sides of the rostrum of $\uparrow$ Ischyrhiza next to slight thinker cartilage on the periphery of the rostrum were the lateral rostral denticles are attached.

From the description of the specimens presented here the presence of this wood-like layer seems to be not restricted only the superficial ophthalmic nerve canals, but rather is more widely extended in the rostrum, similar to that observed in $†$ Schizorhiza (see Kirkland \& Aguillón-Martínez, 2002; fig 8). All three genera present a thick layer of heavily porous cartilage on the sides of the rostrum supporting the lateral series of enlarged of denticles. However, in $\uparrow$ Schizorhiza, this layer is much less porous on the rostrum margins. Based on the presence of fully functional (erect) enlarged denticles of different sizes on the sides of the rostrum of $\dagger$ Onchopristis, we hypothesise a constant addition of rostral denticles. While $\dagger$ Schizorhiza, a rather peculiar sclerorhynchoid, presents a similar rostral morphology which comprises a thin layer of 'wood-like' cartilage and a thick lateral layer of cartilage. The differences in the addition-replacement of lateral rostral denticles and rostral anatomy of $\dagger$ Onchopristis and $\uparrow$ Schizorhiza, suggest differences with other sclerorhynchoids

360 in the use of them (i.e. possibly as a hunting tool or a defence mechanism in $\dagger$ Onchopristis and $†$ Schizorhiza).

Towards the centrum of the rostral cartilages and next to the highly porous lateral layer

363 of cartilage, on both the dorsal and ventral surfaces are two canals, one on each side (Fig. 4A-

364 C). The superficial ophthalmic nerve canal runs on the dorsal surface covered by a layer of 
cartilage and seems to terminate in a cavity next to the supraorbital crest. On the ventral side,

366 the buccopharyngeal nerve canal terminates at the base of the nasal capsules. Both canals

367 become narrower towards the tip of the rostrum, and in several places, are covered by the

368 'wood-like' cartilage suggesting that this cartilage entirely covered the canals.

A

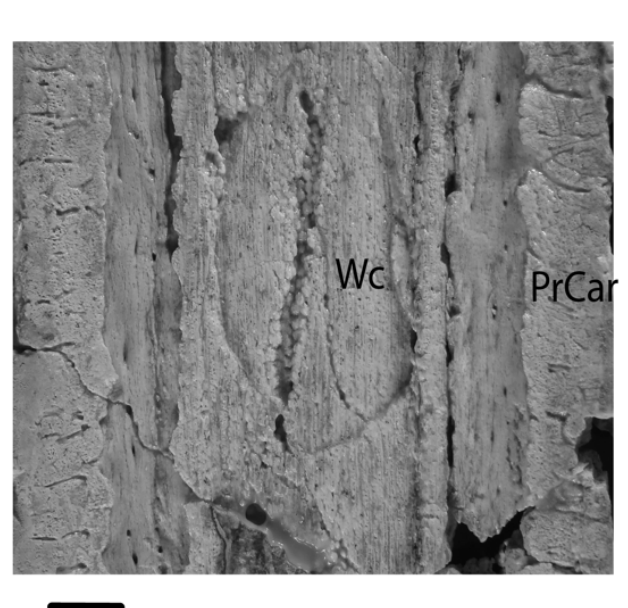

B
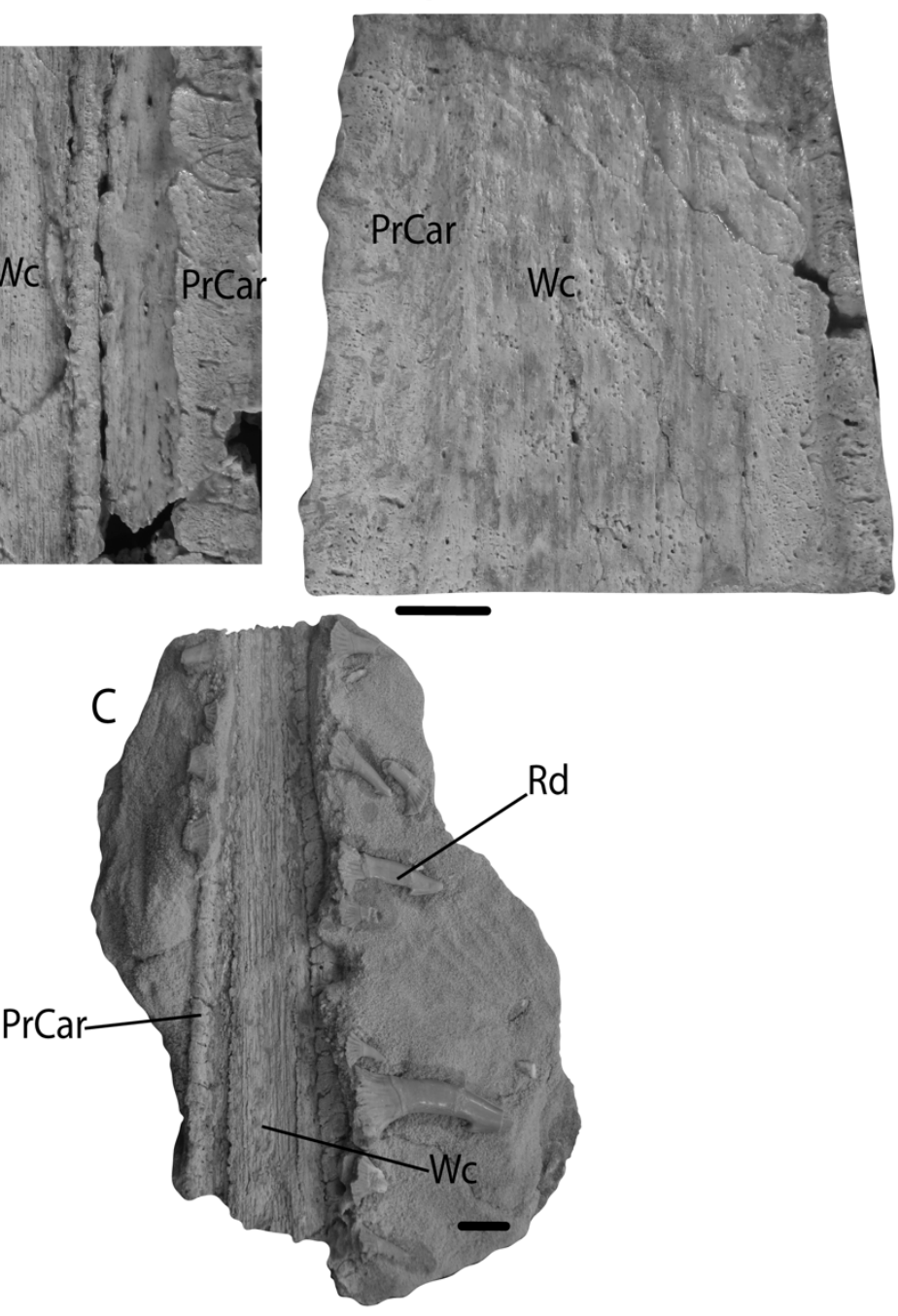

370 Figure 4. A-C, Rostrum of $\dagger$ Onchopristis numidus. A, Ventral surface of IPUW 353500. B,

371 Dorsal surface of IPUW 353500. C, NHMUK PV P 75502. Scale bar: $1 \mathrm{~cm}$.

\section{Lateral enlarged rostral denticles}

All lateral rostral denticles in specimens NHMUK PV P 75502, IPUW 353500 and IGR 
display a small flat base composed mostly of osteodentine and a large-cap composed entirely

377 of orthodentine, with an external layer of enamel, and a characteristic barb on the apical

378 posterior margin of the denticle. Strongly marked cutting edges, accompanied by rectilinear

379 crests, are developed on both anterior and posterior faces of the denticles (Fig. 5). The presence

380 of these cutting edges and the lack of abrasion patterns on the denticles cap suggest that these 381 denticles were not used to probe in the sediment.

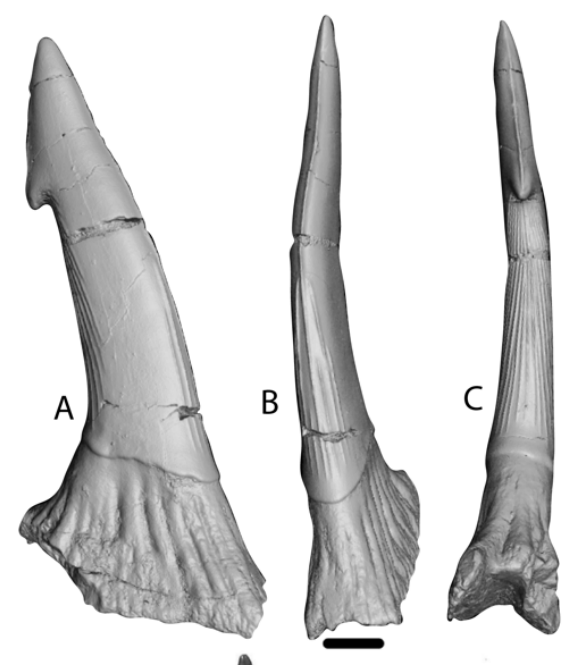

383 Figure 5. Enlarged rostral denticles of $\uparrow$ Onchopristis. A-C, micro-CT-based volume rendering 384 of denticle collected along with the specimen IPUW 353500 from Morocco: (A) dorsoventral, 385 (B) anterior, and (C) posterior view. D-G, denticles collected Egypt (Werner, 1989; plate 19, 386 figs. 2a-d): (D) posterior view, (E) dorsoventral, (F) anterior, and (G) base. Scale bar: 1mm. 
389 Denticles with multiple numbers of barbs were sporadically collected in Morocco (Fig

390 6). These denticles have similar dimensions to single barbed denticles, indicating that there is

391 no correlation between denticle size and barb numbers and that the number of barbs is not a

392 function of ontogenetic stages (Fig 6A). The presence of multiple barbed denticles in the

393 Egyptian and Moroccan localities suggests the sporadic development of double and even triple

394 barbed denticles within †Onchopristis numidus (Stromer, 1917; plate 1 fig. 9 and 1; Werner,

395 1989; plate 20, fig. 1a and 1b, 3 and 6-7) including a three barbed specimen (Wegner, 1989;

396 plate 20, fig. 5).
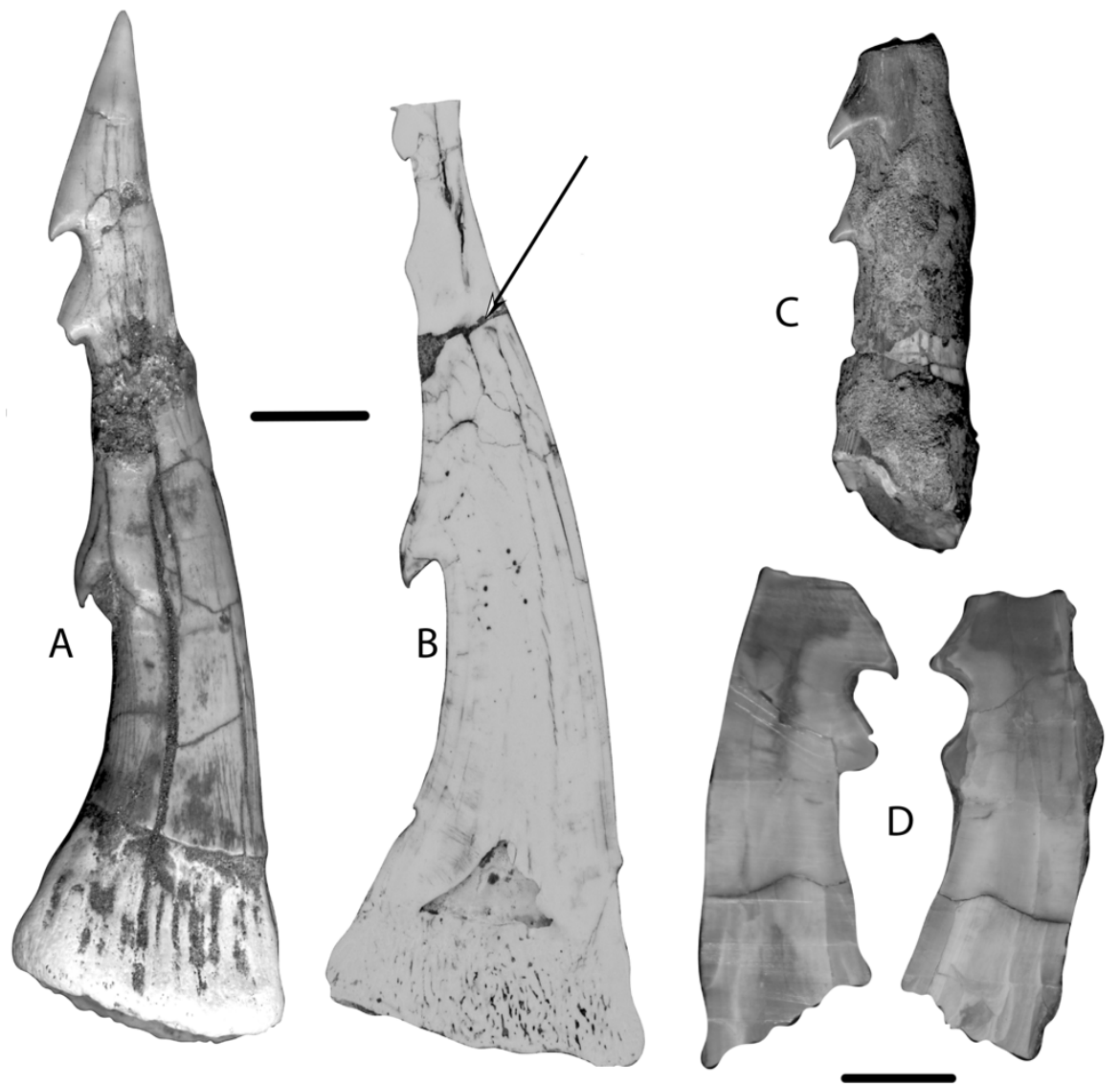

398 Figure 6. A and C Rostral denticles with multiple barbs bought in Morocco. A, Denticle composed of two different denticles brought from a fossil dealer in Morocco NHMUK PV P74053. B, Sagittal section of denticle, the section where the denticles were glued marked with 
an arrow (single barb base attached to a double barbed tip denticle). D, Sagittal section of

402

403

404

405

406

407

408

409

410 denticle in $\mathrm{C}$ that revealed no modifications NHMUK PV P74053. Scale bar: $1 \mathrm{~cm}$.

Isolated denticles present various barb sizes despite the similar size of the denticles (Fig. 7C). The difference in barb size associated with the rostral denticles could be related to their position along the rostrum. Therefore, the barb grows with the denticle during its development. Sections and micro-CT scan of denticles revealed a pulp cavity projecting beyond the base and narrowing significantly to a very thin, almost absent canal when it reaches the barb region, suggesting that the barb could reach a fixed size faster than the remaining portions of the denticle cap (Fig 7A-B).
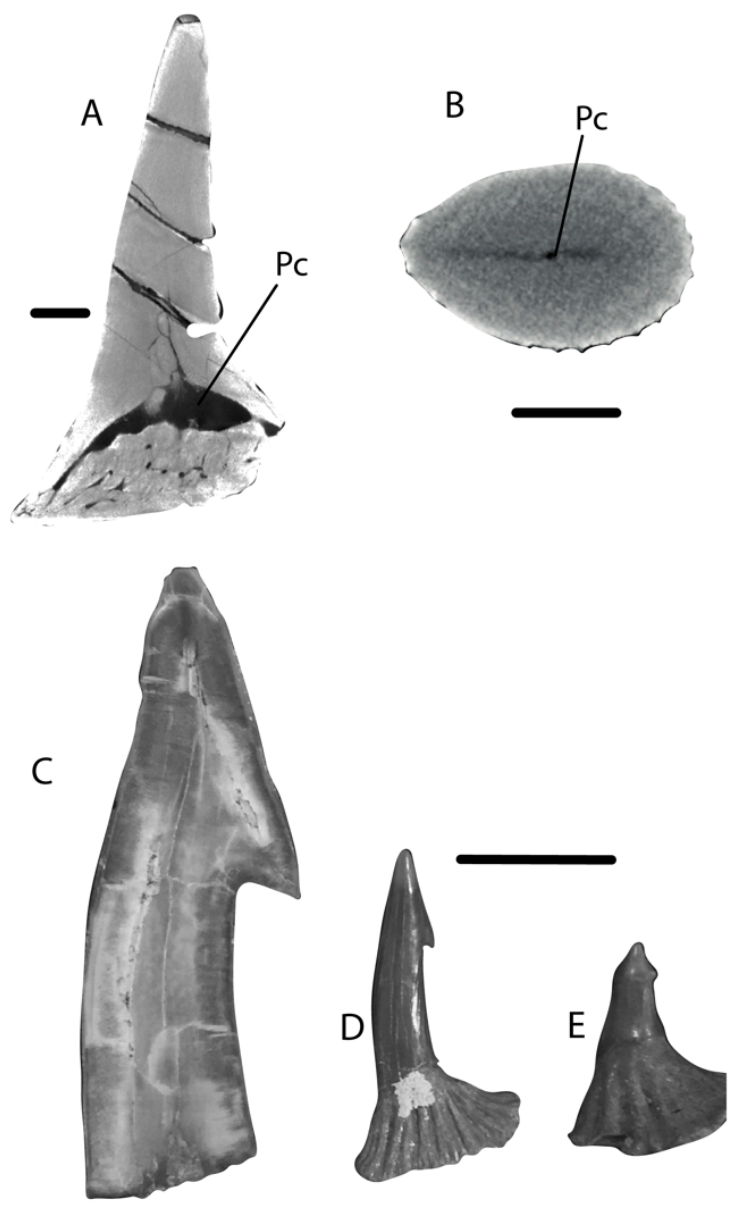

412 Figure 7. Rostral denticles of $\dagger$ Onchopristis numidus found in the "Kem Kem Beds" NHMUK 413 PV P74045. A, CT scan of denticles (scale bar: 1mm). B, Transverse section of denticle (scale 
414 bar: $2 \mathrm{~mm}$ ). C Lateral section of the tip of rostral denticles. D-E, Smaller denticles with 415 different barb sizes (scale bar: $1 \mathrm{~cm}$ ).
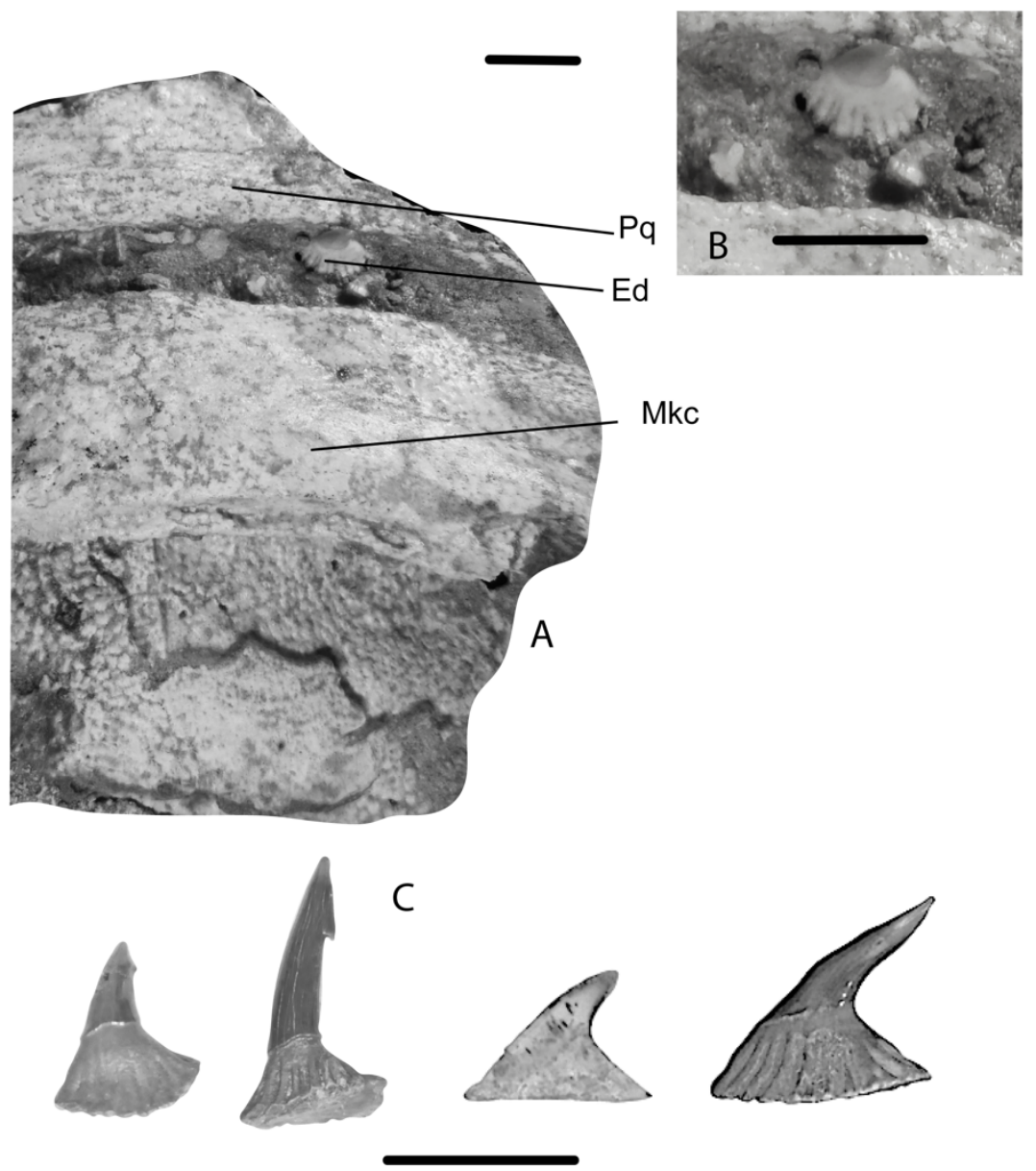

417 Figure 8. A, Mouth of $\uparrow$ Onchopristis numidus (IPUW 353500). B, Close up view of enlarged 418 denticle in the mouth. C, Disarticulated denticles with similar morphology found in the "Kem 419 Kem Beds" collection sites: KK1 (easting: 382819, northing: 3501936 UTM) and KK3 420 (easting: 416828, northing: 3418567 UTM). Scale bar: $1 \mathrm{~cm}$.

Enlarged denticle series: Different morphologies of enlarged denticles possibly attributed to $†$ Onchopristis numidus have been reported in Egypt (e.g. Stromer, 1927, plate 1, fig. 30b-32b; Werner, 1989, plate 20, fig 8-9) and were collected in Morocco (Fig. 8A-C) . The presence of barbless and curved denticle between the jaws of specimen IPUW 353500 (Fig. 8A) and its morphological similarities with the lateral rostral denticles (i.e. a narrow base 
composed of osteodentine with several ridges on the sides, well differentiates from the

428 orthodentine filled cap) confirms the presence of multiple series of enlarged denticles in $\dagger$ Onchopristis numidus. Its placement in the mouth indicates displacement of the denticle

430 during the taphonomic process (i.e. not preserved in situ). However, from its position and the 431 comparison with those of $\uparrow$ Sclerorhynchus atavus NHMUK PV P 4776 and Pristiophorus 432 lanae (see Welten et al. 2015 figs. 6c and 8e) we hypothesise that this denticle corresponds the lateral cephalic series.

The presence of different enlarged series of denticles in $\dagger$ Onchopristis numidus that vary according to their position in the rostral and cephalic regions is similar to that of other sclerorhynchoids (e.g. †Sclerorhynchus Welten et al., 2015; Underwood et al., 2016).

437 Furthermore, the subsequent lateral section of differently shaped free denticles found in the localities showed no evidence of any projection on their posterior margins (Fig. 8B-C), suggests that the development of the barb is restricted only to the lateral series of the rostrum. Replacement of enlarged rostral denticles: We identified three different size classes plus a replacement one in the lateral series of enlarged denticles of the rostrum of $\uparrow$ Onchopristis

442 numidus. With large denticles intercalated with smaller ones and vice versa (i.e. large denticles 443 intercalated with smaller ones) in a single line. This type of arrangement is new in batoids, 444 including Pristidae, in which the single lateral rostral series is composed of a single line of 445 continuously growing rostral denticles. Miller (1974) observed that the size arrangement and 446 number of rostral teeth are established during the embryological stages in Anoxypristis 447 cuspidata and Pristis pristis Welten et al. (2015) propose a similar observation regarding the 448 arrangement and number of rostral denticles in pristioids. However, this last work suggests that 449 if denticles are added, it will be caudally near the base of the rostrum or closer to the tip, but 450 only more pristioids embryonic material will confirm this. 

hypothesise that in this species the denticles are periodically added across the rostrum as it

454 grows and develops over time (Fig. 9). The presence of fully erect small denticles followed by larger ones, as observed in specimen IPUW 353500 and IGR 2818, suggests a seriated appearance of the rostral denticles beginning with smaller denticles and subsequently followed by larger ones (Fig. 9A-B). The three-size cluster of rostral denticles with a mirrored arrangement (i.e. similar-sized denticles placed on opposite sides in dorsal view) recognised in IGR 2818, is interpreted to be the result of synchronised development on both sides of the rostral denticles. This mirroring pattern is unnoticeable or less conspicuous at the tip of the rostrum, probably because it is a more fragile region and denticles in this area could be more susceptible to fracture due to taphonomic processes. The presence in both specimens (IPUW 353500; IGR 2818) of small denticles (G1) and larger denticles (G2 and G3) with fully enamelled caps suggest that denticles do not gradually grow, but instead that larger denticles are periodically added as the animal grows (Fig. 9C). Both the arrangement and addition sequence are different from other sclerorhynchoids (e.g. Sternes \& Shimada, 2019; Welten et al., 2015; Underwood et al., 2016; Smith et al., 2015). et al., 2015 and Underwood et al., 2016). With some notable differences: In $†$ Onchopristis numidus both small and large rostral denticles seems to lack a differentiated degree of mineralisation and present a cap densely filled with orthodentine, whereas rostral denticles in Pliotrema warreni differ in the mineralisation pattern between older (larger) and younger (smaller) denticles (Welten et al., 2015). In addition, the triplet arrangement observed in the rostral denticles of Pliotrema warreni is not always present in $\dagger$ Onchopristis numidus in which denticles of the same size as those of the functional generation replace or occupy the available 
space. This arrangement is similar organisation to that reported for other sclerorhynchoid

477 species (e.g. $\dagger$ Sclerorhynchus, Welten et al., 2015), in which some replacement denticles are

478 so closely associated with the existing functional ones that they seem to appear in pairs (Fig.

4792 , denticles marked with an arrow)".
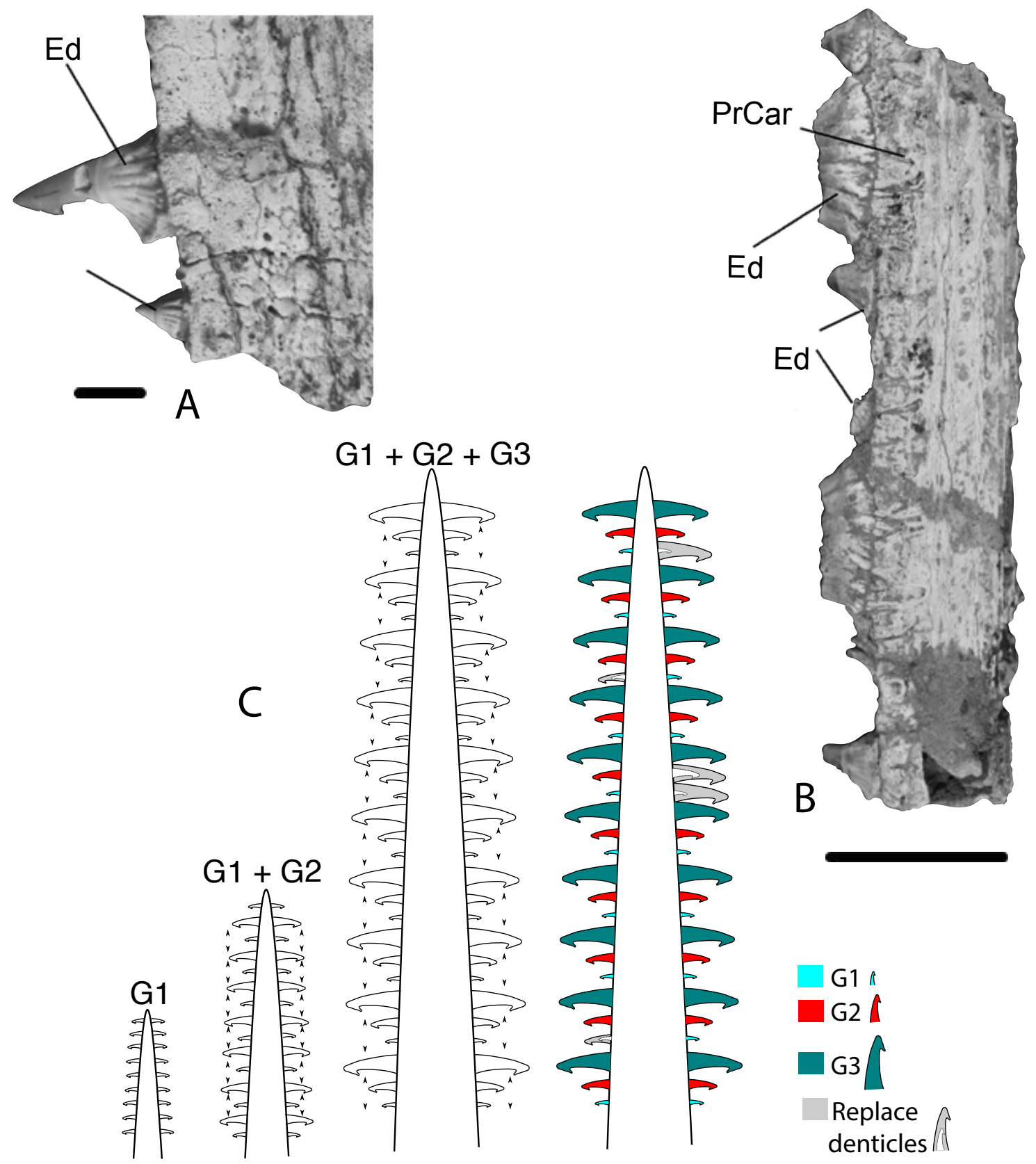

480

481 Figure 9. Fragment of the rostrum of $\dagger$ Onchopristis numidus. A, IPUW 353500 (scale bar:

482 1 cm). B, NHMUK PV P 75503 (scale bar: 5cm). C, Hypothetical scheme of the growth and 
484 replacing smaller ones that fell.

485

486
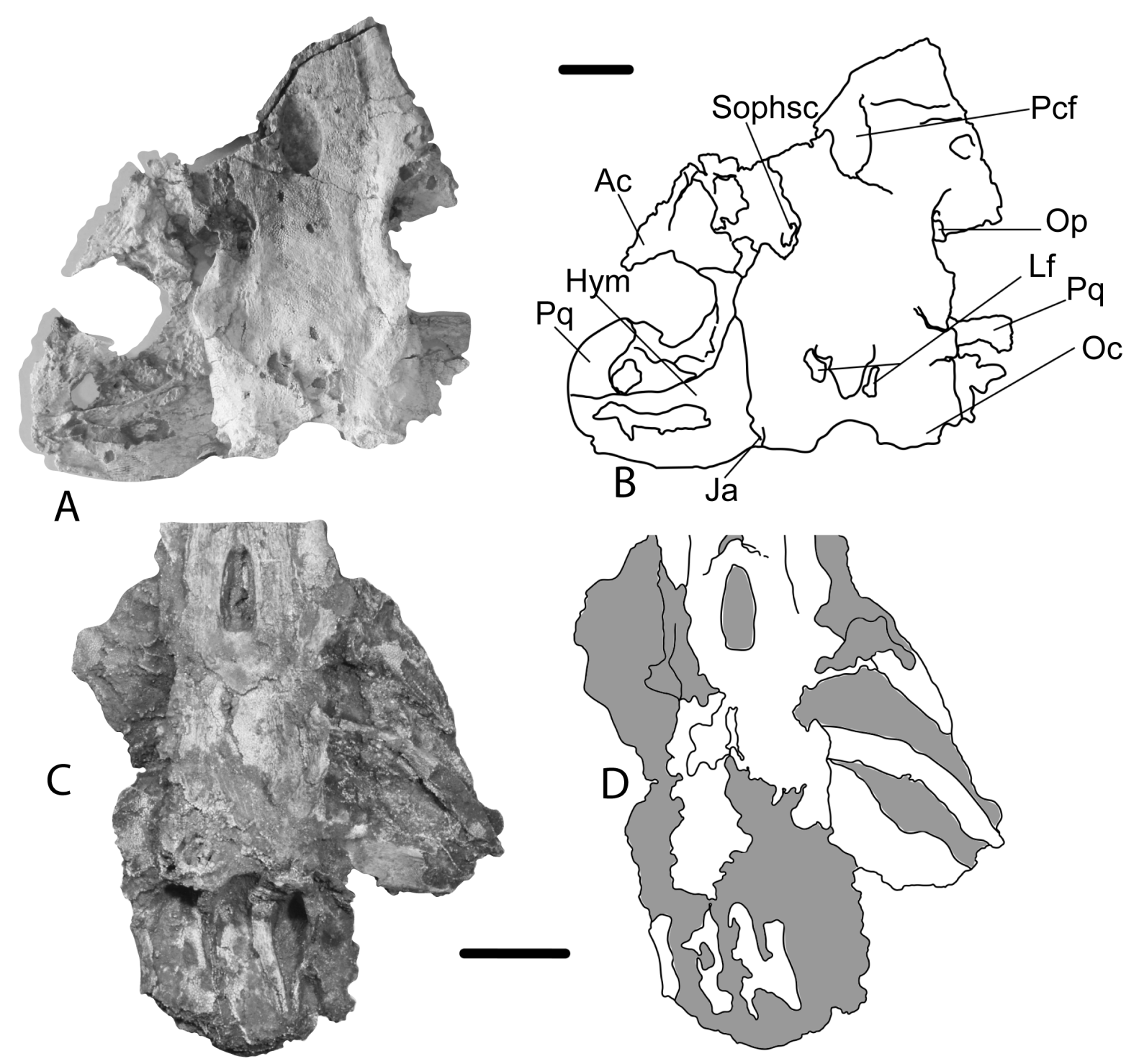

488 Figure 10. A-B, Neurocranium of $\uparrow$ Onchopristis numidus. A, picture of IPUW 353500. B, line

489 drawing. C, picture of IGR 2818. D, line drawing. Scale bar $4 \mathrm{~cm}$. Note: darken areas on 490 drawing represent sediments.

\section{Neurocranium}


Only the postnasal region and part of the posterior edge of the nasal capsules can be

494 addressed here, as the most anterior part of the nasal capsules is missing. The neurocranium is 495 box-like and rectangular shaped, with an oval-shaped precerebral fenestra located near the base 496 of the rostrum at the centre of the anterior part of the neurocranium (Fig. 10). The dorsal surface 497 of the left nasal capsules is not discernible, because it is heavily crushed. In ventral view, the 498 posterior region of the right nasal capsule is preserved and presents a deep nasal fenestra that 499 smoothly progresses into the rostrum. The buccopharyngeal nerves cavities are located on the 500 ventral surface anterior to the nasal capsules (Fig, 11 A-B).

501 The profile of the antorbital cartilage is triangular, with its narrow distal edge pointing 502 posteriorly and its wide proximal edge articulating with the nasal capsule (Fig. 11 A-B). Even 503 though the neurocranium presents some crushing dorsoventrally, the supraorbital crest stands 504 above the dorsal surface of the chondrocranium and does not cover the eye cavity. The orbital 505 cavity is large and houses a well mineralized optic peduncle; additional nerve foramina were 506 not observed (Fig. 11 C-D). Next to the supraorbital crest is the cavity for the superficial 507 ophthalmic nerve (Fig. $10 \mathrm{~B}$ ). The postorbital region is rectangular and narrow with a small 508 triangular postorbital process. In the otic region, the orbital fissure is above the lateral 509 commissure and below the postorbital crest. The lateral commissure covers part of the 510 hyomandibular branch of the facial nerve foramen (Fig. 11 C-D). The lymphatic foramina are 511 present in the posterior part of the neurocranium. The jugal arches follow the otic region and 512 are located anteriorly to the occipital condyles which are well developed and expanded laterally 513 forming a broad and deep articulation facet for the anterior lateral process of the synarcual 514 (Fig.10). 
518 at tip ratio $=0.018$, with its proximal end articulating to the neurocranium, and its narrow

519 distal end connected between the palatoquadrate and Meckel's cartilages. A section of the 520 dorsal surface of the hyomandibula is missing; however, the remaining parts are slightly 521 elevated, which could indicate the presence of a process for muscle articulation. (Fig 10).
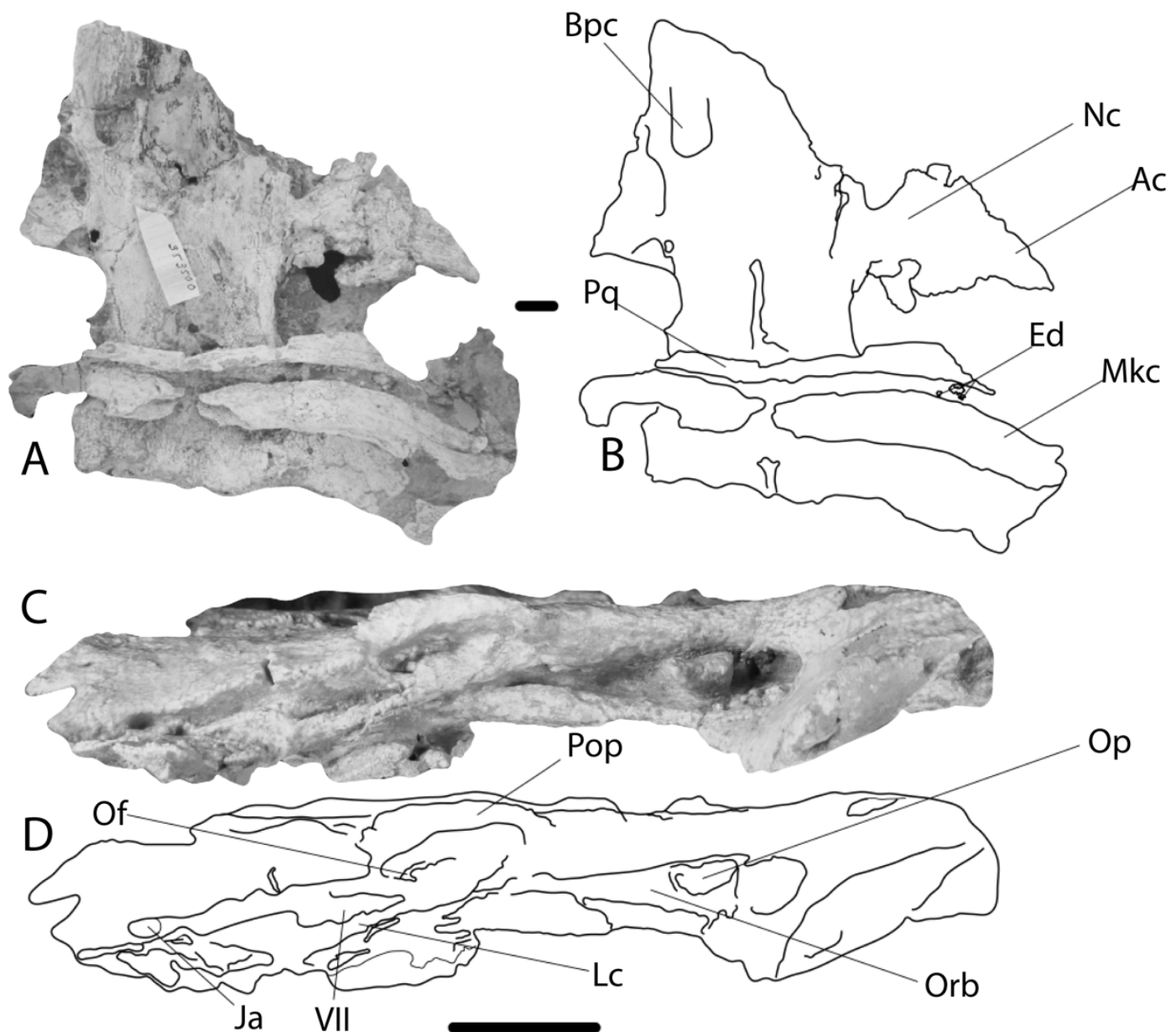

523 Figure 11. Neurocranium of $\dagger$ Onchopristis numidus (IPUW 353500). A, Ventral view. B,

524 Line draw. C, Lateral view. D, Line draw. (A-B, scale bar: $2 \mathrm{~cm}$ ). (C-D, scale bar: $5 \mathrm{~cm}$ ).

\section{Jaw cartilages}

Only part of the Meckel's and palatoquadrate cartilages are observable in ventral view

(Fig. 11 A-B). The palatoquadrate is thin and narrows progressively towards the symphysis

(Fig. 11 A-B). In ventral view, there is no clear articulation with the neurocranium, the 
530 Meckel's cartilage and palatoquadrate are present, and both jaw elements seem to be supported

531 by the hyomandibula. The palatoquadrate and Meckel's cartilage antimeres are not fused and

532 connected at the symphysis. The Meckel's cartilage is wider than the palatoquadrate but also

533 becomes narrower towards the symphysis (Fig. 11 A-B).

$534 \quad$ Oral teeth: Teeth of $\dagger$ Onchopristis numidus have been figured multiple times (e.g. by 535 Stromer, 1927, plate I, figs 1-4, under the name $\uparrow$ Squatina aegyptiaca; by Werner (1989, plates 536 35-37), under the name $\dagger$ Sechmetia aegyptiaca. The teeth figured on plates $21 \& 22$ by Werner 537 (1989) and described as $\dagger$ Onchopristis, probably belong to a different sclerorhynchoid such as $538 \uparrow$ Renpetia) and are similar to those of $\uparrow$ O. dunklei (Welton \& Farish, 1993; Kriwet \& Kussius, 539 2001,text-fig. 4; Cappetta, 2012; Fig. 370M-R; Vullo et al., 2003: pl. 2, fig. 6).

540 Both species have teeth with a sharp and acute cusp, that bent lingually (Fig. 12 C, G,

541 K; Fig. $13 \mathrm{~J}, \mathrm{~L})$. The labial apron is narrow, with a blunt distal edge that projects anteriorly and 542 surpasses the root and present pair of incipient lateral cusplets (Fig. 12 A, E; Fig. 13 O, K, S). 543 Several teeth collected in Morocco present a double-lobed labial apron (Fig. 12 A, E, D, H). 544 Some teeth also have a cutting edge on the labial and lingula crown faces (Fig. 13 A-E). All 545 teeth display well developed cutting edges, which are continuous between the cusp and lateral 546 cusplets (Fig. 12; Fig. $13 \mathrm{~J}, \mathrm{~L}$ ). The lingual uvula is absent (Fig $12 \mathrm{C}, \mathrm{G}$ ), and the root is bilobed 547 and laterally projected (Fig. 12 B, F; Fig. 13 P).

548 Cross-sections of the oral teeth revealed the presence of a large pulp cavity in the root 549 that extends apically into the crow where it becomes narrower as it progresses towards the apex 550 (Fig. 13 G, K, R.). 

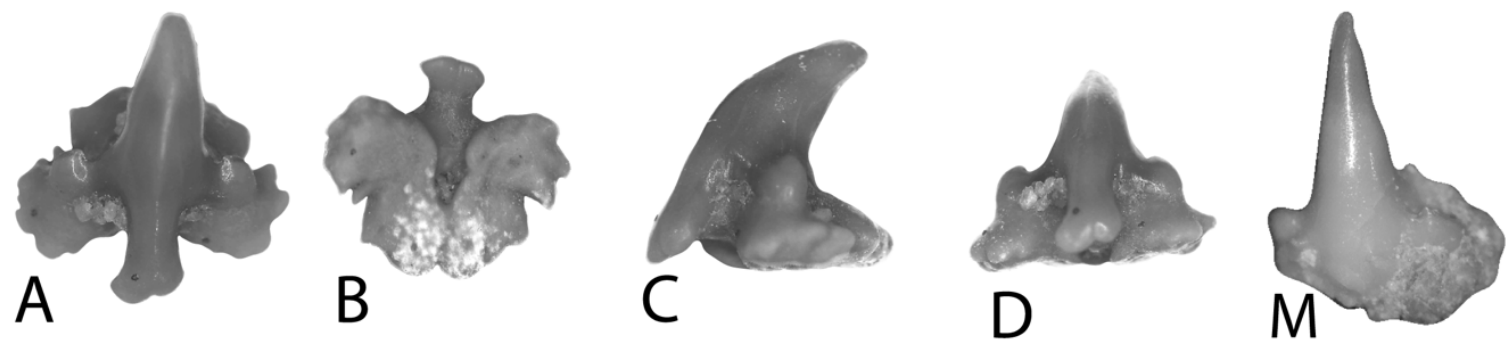

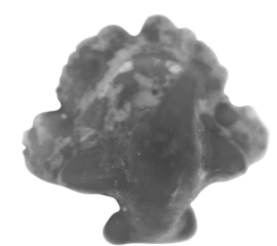

$\mathrm{E}$

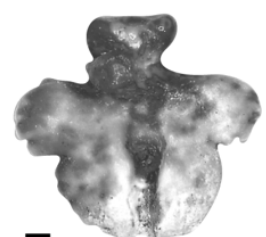

$\mathrm{F}$
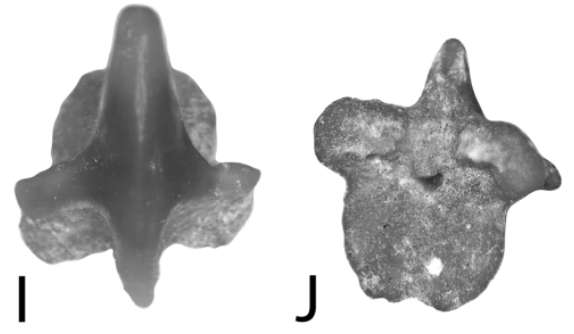
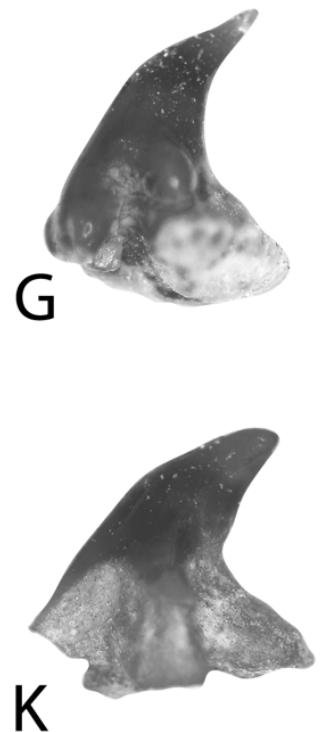
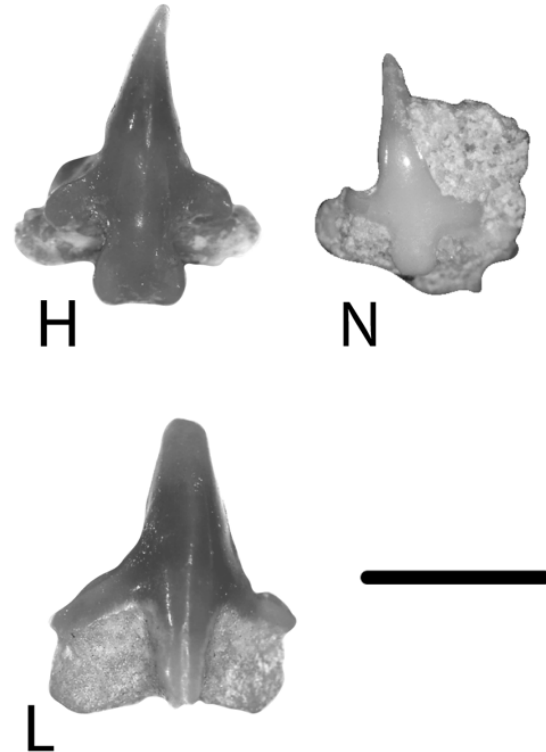

551

552 Figure 12. A-L. Oral teeth of †Onchopristis numidus found in the "Kem Kem Beds",

553 collection site Boulalou (KK5: easting: 418413, northing: 3479178 UTM, zone: 30) NHMUK

554 PV P 74050. M-N Teeth extracted from the preparation of specimen IPUW 353500. (A, E, I,

555 D, H, L, M and N) Labial face. (B, F and J) root. (C, G, and K) profile view. Scale bar: $2 \mathrm{~mm}$. 


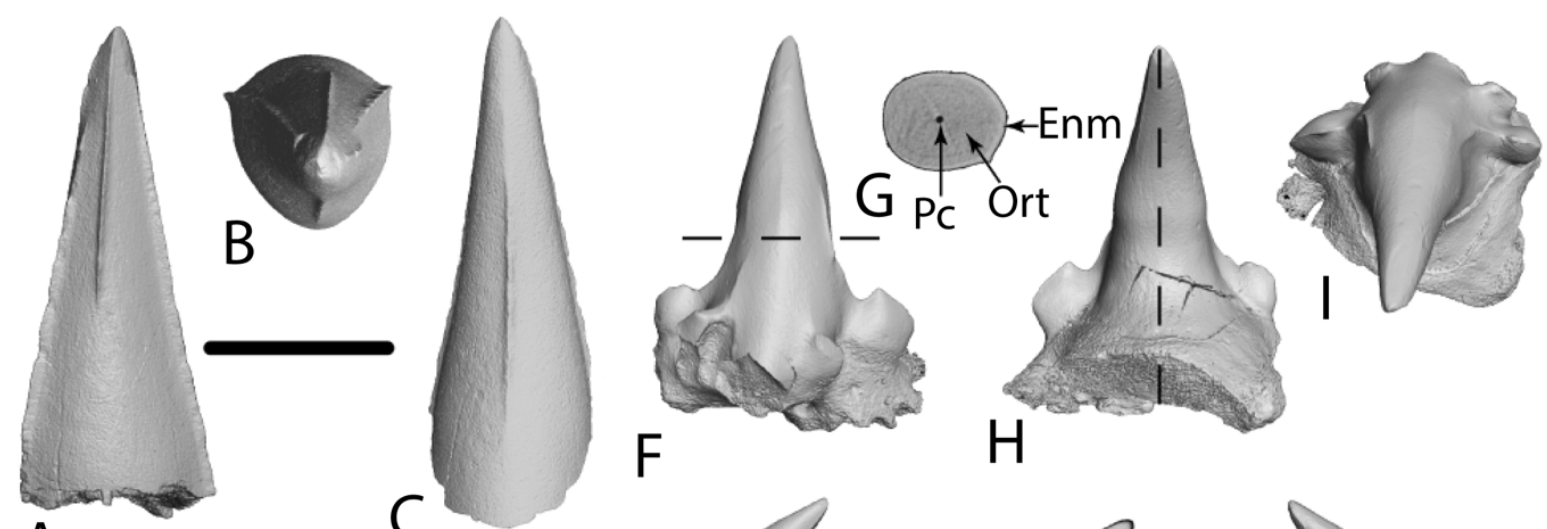

A

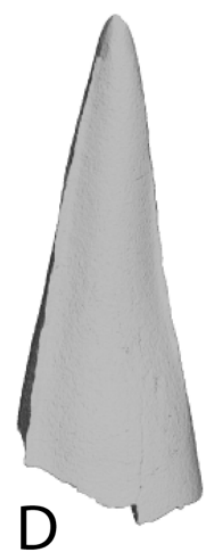

$\mathrm{E}$

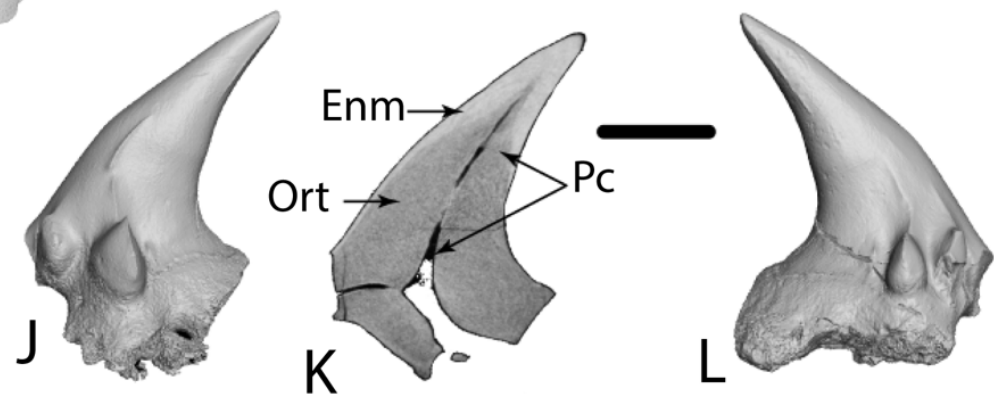

Figure 13. Micro-CT-based volume renderings and virtual sections of oral teeth of $\uparrow$ Onchopristis numidus found associated with IPUW 353500. A-E, broken main cusp in (A)

560 labial, (B) occlusal, (C) lingual, (D) medial, and (D, E) profile views. F-L, incomplete tooth

561 lacking part of the labial apron and root in (F) labial, (H) lingual, (I) apical, and (J, L) profile

562 views; tooth sections in $(\mathrm{G})$ axial and $(\mathrm{K})$ sagittal aspects; $\mathrm{M}-\mathrm{S}$, tooth with a broken main cusp

563 in (M) labial, $(\mathrm{N})$ lingual, $(\mathrm{O})$, occlusal, $(\mathrm{P})$ basal, and $(\mathrm{Q}, \mathrm{S})$ profile views tooth section in $(\mathrm{R})$.

\section{Synarcual}


566 odontoid process (synarcual lip) that forms part of the articulation surface for the synarcual

567 with the neurocranium along with the extensive anterior lateral process that mirrors the

568 odontoid processes in the neurocranium. This process and the depth of the odontoid process

569 suggest a close and not very mobile articulation with the neurocranium (Fig. 14). The central

570 portion of the synarcual is well developed displays some spino-occipital foramina (the actual

571 number remains unknown as only a portion of the synarcual is preserved). The medial crest

572 anterior part is missing; however, is remaining portions are thin and well developed, and seems

573 to have been folded during taphonomic processes. Only the right lateral stay is visible, and it

574 becomes progressively narrower backwards. Its distal end is well developed and flattened, and 575 it probably was dorsally directed during life (Fig. 14 A-B). In ventral view, no vertebral centra 576 are observable, which suggests that the vertebra centra did not pass the midpoint of the 577 synarcual (Fig. 14 C-D), as in other sclerorhynchoids (Villalobos et al., 2019a)

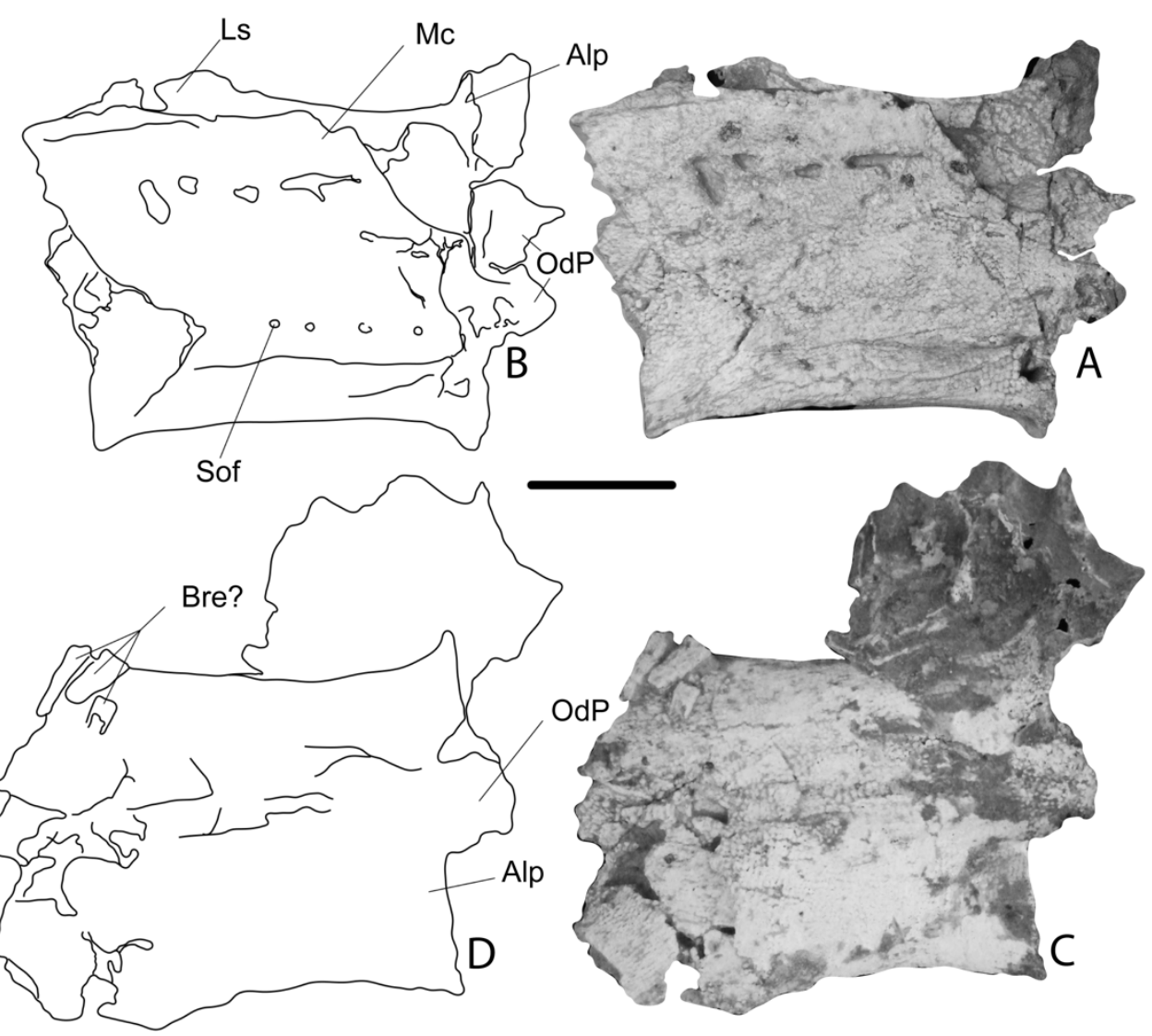


579 Figure 14. Synarcual of $\uparrow$ Onchopristis numidus (IPUW 353500). A, dorsal view. B, line draw.

580 C, ventral view. D, line draw. Scale bar: $5 \mathrm{~cm}$.

581

582 Vertebrae

583 The vertebral centra of $\uparrow$ Onchopristis consist of the corpus calcareum and the

584 intermedialia as in other chondrichthyans. The corpus calcareum is well mineralized and

585 shows clear and opaque bands suggesting a cyclical deposition of mineral. Whether this

586 pattern was seasonal as in other chondrichthyans, remain ambiguous for the moment (Fig.

587 15).
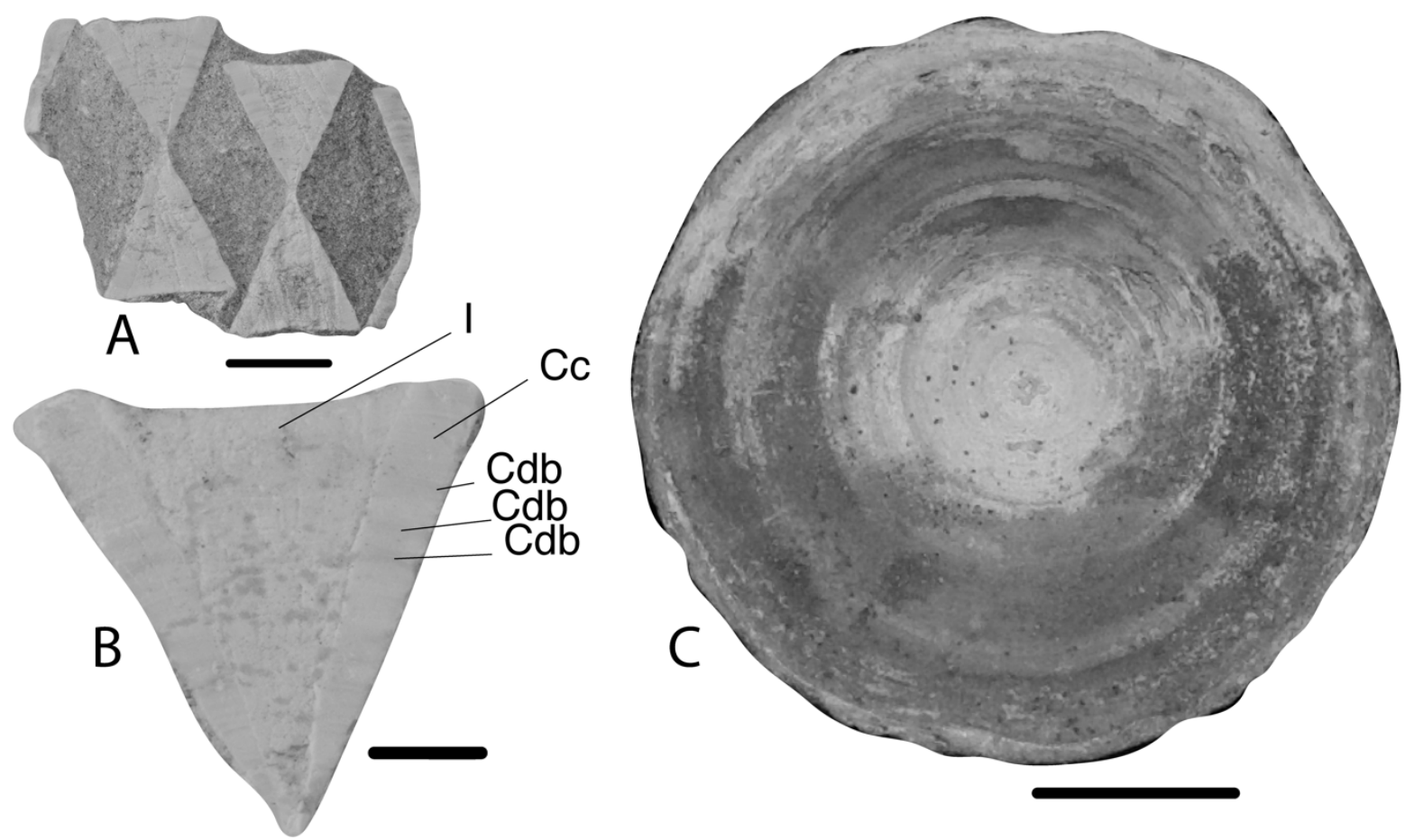

588

Figure 15. A-B. Vertebral centra of †Onchopristis numidus from the "Kem Kem Beds"

590 Collection sites Boulalou (KK5: easting: 418413, northing: 3479178 UTM) NHMUK PV P

591 74052. (A-B) Sagittal section of vertebra. (C) Articulation surface of the vertebra. Scale bars:

$5921 \mathrm{~cm}$. 
The rostrum also presents a small series of denticles at the base of the enlarged rostral

596 denticles and on the ventral surface (Fig. 16 G). Two morphologies are present, both with a

597 rounded well enamelled cap and a stellated base with fringes that projects just out below the

598 cap and can be distinguished by the presence of a central cusp (Fig. 16 A-F).
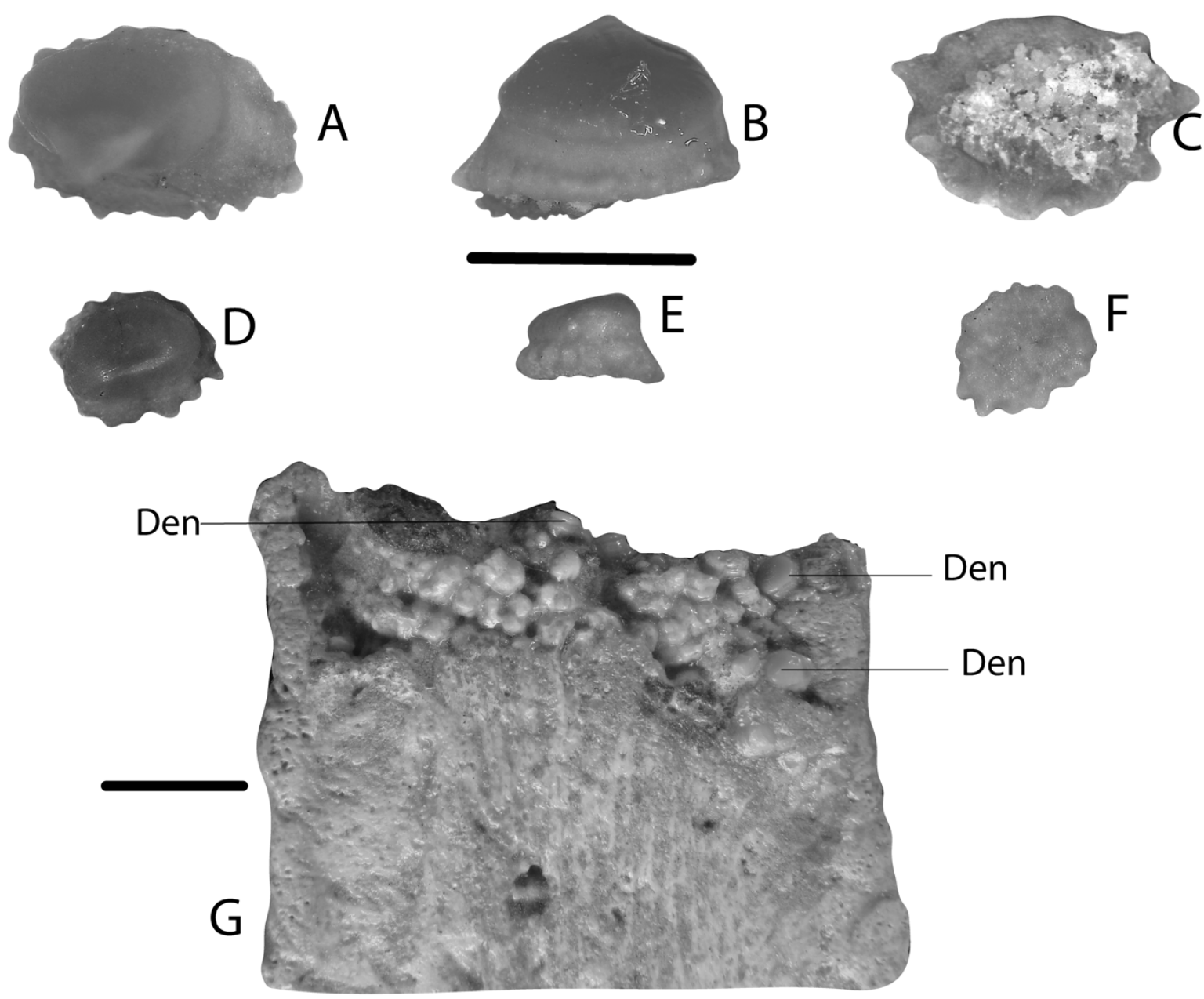

600 Figure 16. A-F Ventral rostral denticles from the section of the rostrum of $\dagger$ Onchopristis 601 numidus (NHMUK PV P 75502). A-C, Morpho 1. D-F, Morpho 2 (scale bar: 2mm) NHMUK

602 PV P 74051. G, anterior part of the ventral surface of IPUW 353500 rostrum (scale bar: $1 \mathrm{~cm}$ ). 603 As in other fossil assemblages (Werner, 1989), the occurrence of $\uparrow$ Onchopristis in the "Kem Kem Beds" coincides with that of "Peyeria-like" denticles (Fig. 17). Cappetta (2012) 
noted that these two batoids are commonly found together, proposing that $\uparrow$ Peyeria Werner,

6071989 was, a synonym of $\dagger$ Onchopristis and the $\uparrow$ Peyeria remains were, in fact, dermal

608 denticles of $\dagger$ Onchopristis. Recently, similar enlarged dermal denticles were reported for

609 †Ischyrhiza mira Leidy, 1856 by Sternes \& Shimada (2019) in Campanian-lower

610 Maastrichtian of Tennessee and Alabama, U.S.A, suggesting that this feature might be even

611 more common among sclerorhynchoids. The presence of these types of enlarged body denticles

612 in Morocco agrees with Cappetta (2012) and Sternes \& Shimada (2019) interpretations.

614 (Werner, 1989, plate 41, figs. 1-4; Sternes \& Shimada, 2019, text-fig. 4e-f). They present a

615 thick enameloid layer on the anterior edge of the denticles. Additional cross-sections revealed

616 a small pulp cavity followed by a thin, not very porous laminar layer, on which a thick layer of

617 highly vascularised osteodentine that reaches the tip of the denticle is deposited (Fig. 17 C).
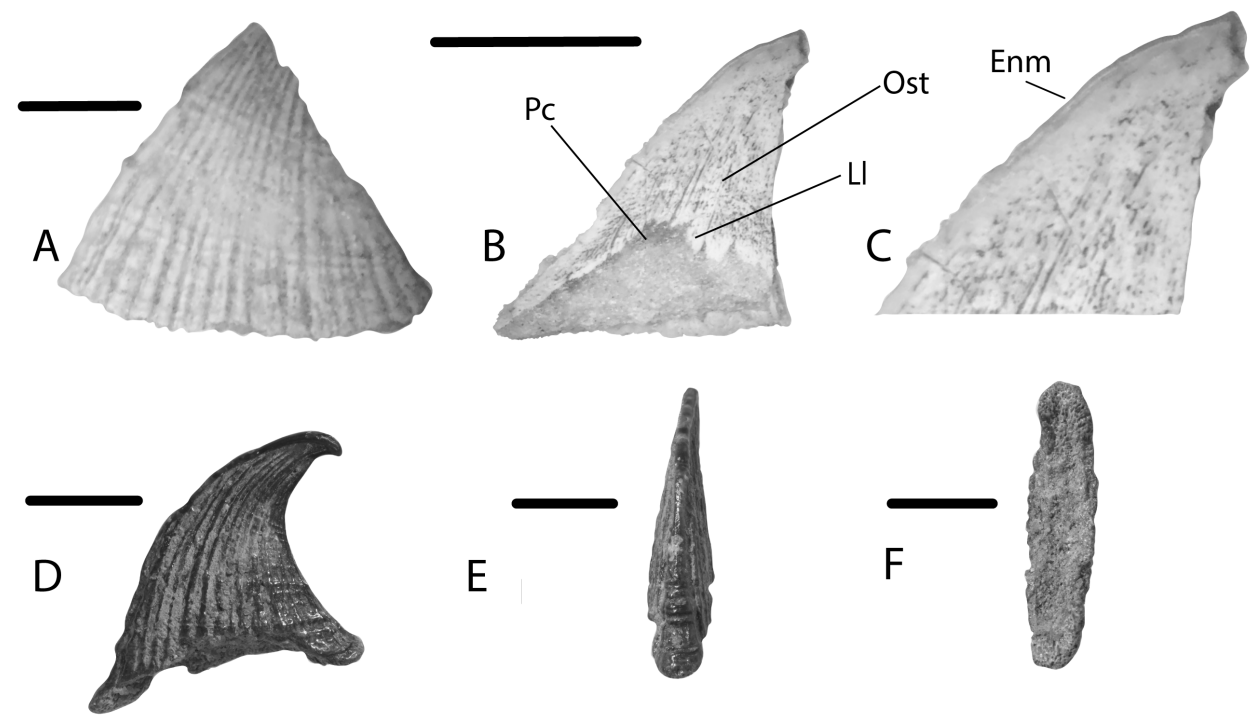

618
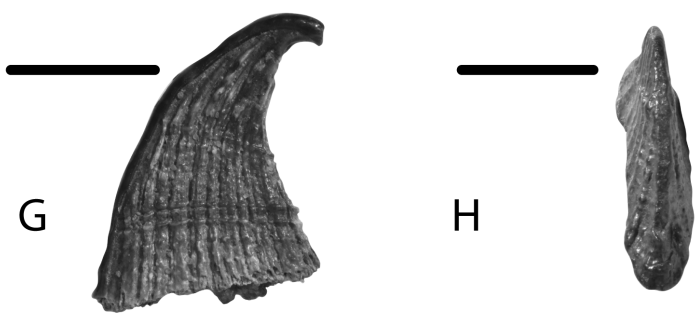

619 Figure 17. Enlarged dermal denticles of $\uparrow$ Onchopristis numidus from the "Kem Kem Beds". 
621 C.U personal collection, lateral view. D-F, IGR 2819, lateral, anterior and basal views. G, IGR 622 2820, lateral view. H, IGR 2821, antero-apical view. Scale bars: $1 \mathrm{~cm}$.

623

624 PHYLOGENETIC ANALYSIS

A. Consesus trees recovered with TNT

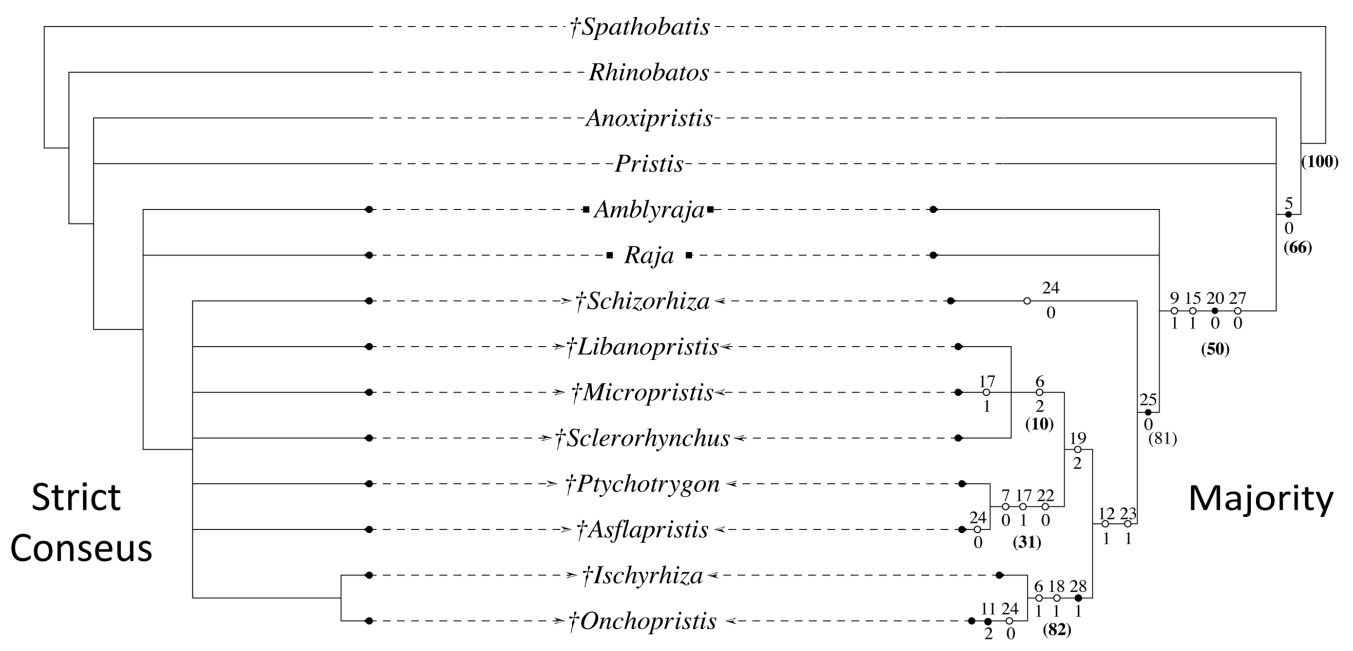

B. Consesus trees recovered with TreeSearch

625

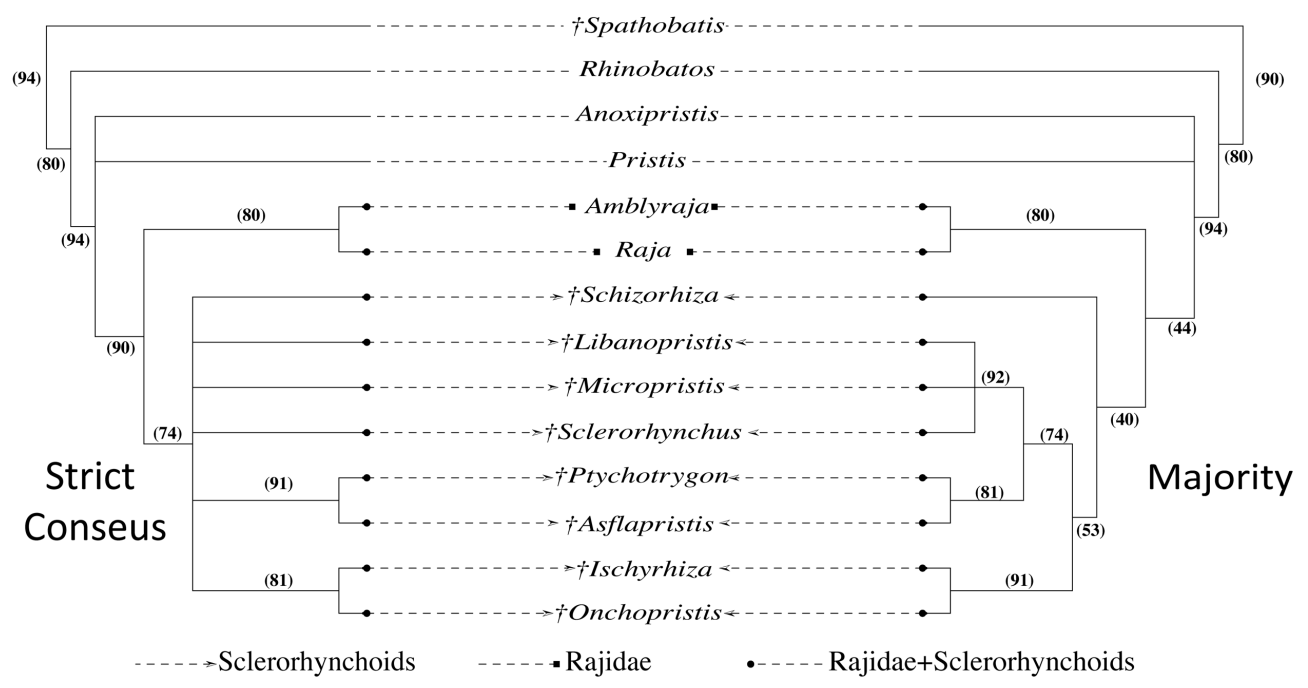

626 Figure 18. Phylogenetic trees recovered by the different analysis used in the present study. (A)

627 strict consensus and majority rule trees produced by the TNT analysis. (B) strict consensus and 628 majority rule trees produced by the TreeSearch analysis: Clade support values from the 629 Jackknife analysis displayed inside the parenthesis. Character supporting nodes of TNT's 
majority rule tree (MRT): Black circles characters recovered by both consensus methods;

631 White circles characters recovered only by MRT.

The character matrix for the phylogenetic analysis used here is a modified version from that used by Villalobos et al. (2019b). The main changes include recoding of the polymorphic characters 5, 6 and 9, which were changed for Raja and Amblyraja (see supplement material; Character discussion). These features refer to the absence/presence of malar thorns, which are developed only in male rays (Aschliman et al., 2012). Three different coding schemes were considered for these characters, that included removing those characters, leaving them as a polymorphic character and coding them as presence, small topological changes resulted from these different codifications (supplement material). However, we consider that regardless of the sexual dimorphism link of these characters, the malar thorns are features that correspond to the genera and should be coded as present. changed for Anoxypristis to present as its teeth show a variably developed lateral uvula (e.g. Underwood et al., 2011; Cappetta, 2012), but in general, seems to be present. $\uparrow$ Ptychotrygon, following the observations made on $\uparrow$ Ptychotrygon rostrispatula by Villalobos et al. (2019b) and four characters were included (Chrs. 25-29) to increase the morphological variance observed within sclerorhynchoids.

650 The TNT analysis recovers 13 most parsimonious trees of 41 steps with a consistency index of 0.78 and a retention index of 0.85 , whereas the TreeSearch analysis recovered a 41 steps tree. Both strict consensus trees (Treesearch and TNT) place all sclerorhynchoids taxa, including $\uparrow$ Schizorhiza into a polytomy (Fig. 18 A-B, clade support Cs (strict) $=74 \%$, Cs

654 (majority) $=40 \%$ ). In both strict consensus and majority rule trees this clade is supported by 
one shared feature, the lack of a rostral appendix (Fig. 18 A, Character $(\mathrm{Chr}$.) $=25,0$,

656 Consistency index $(\mathrm{Ci})=1$ ) which refers to the absence of thin cartilage attached to the rostrum

657 (see, character discussion in supplementary material). However, the compared anatomy of the

658 process occurring within sclerorhynchoids is unique. In Myliobatiformes, the rostral appendix

659 is polymorphic, some groups present it (e.g. Urotrygon and Potamotrygon) and others do not

660 (e.g. Rhinoptera and Zanobatus). The development of this structure in Myliobatiformes

661 corresponds to the anteromedial growth of the trabecula (i.e. the rostral shaft or rostral

662 cartilage) (Miyake et al., 1992). In platyrhinoids the trabecula does not present mid growth, as

663 a result the appendix is absent, also these taxa develop as similar structure which is referred as

664 a rostral process by McEachran \& Aschliman (2004) and Aschliman et al. (2012). Within

665 torpedinids, the development of the rostrum varies with different embryonic cartilages

666 participating in its formation (e.g. In Torpedo the rostral cartilages develop from the lamina

667 orbitonasalis, whereas in Narcine the rostral cartilages derive from the trabecula, which also

668 presents different chondrification periods) (Miyake et al., 1992). In comparison, the

669 development of rostral cartilages in sclerorhynchoids appears simpler, as they present a good

670 anteromedial growth with no apparent rostral appendix (similar to that of sawsharks),

671 suggesting a convergence between sclerorhynchoids and sawsharks, considering the

672 anatomical differences between these shark and batoid groups (i.e. presence of synarcual and

673 antorbital cartilages). The sclerorhynchoid clade is placed in a sister relation to the Rajidae

674 (Amblyraja and Raja, Fig. 18 A-B, Cs = 80\%). The monophyletic group Rajidae +

675 Sclerorhynchoids (Fig. 18 A-B, Cs (strict) $=90 \%$, Cs (majority) $=44 \%$ ), is supported by four

676 shared features in the majority rule tree and one in the strict consensus (Fig. 18 A). Both trees

677 place the lack of differentiated lateral uvula in teeth (Fig. $18 \mathrm{~A}$, Character $($ Char.) $=20,0, \mathrm{Ci}=$

678 1) as a shared synapomorphy (see, character discussion in supplementary material). It is worth

679 mention that sclerorhynchoids are not the only batoids lacking these projections. All 
680

681

682

683

684

685

686

687

688

689

690

691

692

693

694

695

696

697

698

699

700

701

702

703

704

sclerorhynchoids dentitions reviewed here lack these structures, suggesting more than just a diet adaptation.

Within the sclerorhynchoids clade, two monophyletic groups are recovered by the strict consensus tree estimated with TreeSearch and one with TNT analyses (Fig. 18 A). Both analyses coincide in the grouping of $\uparrow$ Onchopristis, and $\dagger$ Ischyrhiza as a monophyletic group (Fig. 18 A-B, Cs $($ strict $)=81 \%$, Cs $($ majority $)=91 \%$ ). This relation is supported by one common synapomorphy in both strict consensus and majority rule trees, that is the presence of smaller denticles with a round cap associated with the base of the enlarged rostral denticles (Fig. 18 A, Character $($ Char. $)=28,1, \mathrm{Ci}=1)$. The majority tree rule recovered two more shared features for the $\dagger$ Onchopristis and $\dagger$ Ischyrhiza clade, the reason why these characters are not considered a synapomorphy and do not appear in the strict consensus tree (Fig. 18 A) is the presence of ambiguity; for character $18(\mathrm{Ci}=1)$ the coding of $\dagger$ Schizorhiza $(?)$ creates ambiguity. While, for character $6(\mathrm{Ci}=1)$ the uncertainty comes from the collapse of the $\dagger$ Libanopristis, $\uparrow$ Micropristis, $\dagger$ Sclerorhynchus, $\dagger$ Ptychotrygon and $\dagger$ Asflapristis clade (Fig. $18 \mathrm{~A}-\mathrm{B}, \mathrm{Cs}$ (majority) $=74 \%$ ). Of the features, the presence of large denticles associated with the body (Char. 18, 1) is significant as $\uparrow$ Onchopristis and $\dagger I s c h y r h i z a$, as they are currently the only sclerorhynchoids presenting this feature, supporting the closer relationships found between these taxa by the present analysis.

The strict consensus tree estimated with the TreeSearch analysis is better resolved than that of the TNT analysis, recovering another monophyletic group that includes $\dagger$ Asflapristis + $\dagger$ Ptychotrygon (Fig. 18 B, Cs (strict) $=91 \%$, Cs (majority) = 81\%). Three features support the relation (see MRT, Fig. 18 A); (1) lack of enlarged denticle series associated to the rostral cartilages (Char. 7, 0, Ci=1), (2) presence of a transversal crest on teeth (Char. 17, 1, Ci=1) and (3) lack of calcified suprascapula (Char. 22, $0, \mathrm{Ci}=0.5)$ (see, character discussion in supplementary material). 
Measurements established from other studies on Pristidae (e.g. Morgan et al., 2011; Whitty et al., 2014) and those made on †Libanopristis hiram (NHMUK PV P 75075) and $\uparrow$ Ptychotrygon rostrispatula (NHMUK PV P 73630, 75496), suggest an approximate proportion between the length of the rostrum and the standard length to range from $21-30 \%$ in sclerorhynchoids. This scaling suggests that the specimens of $\uparrow$ Onchopristis described here had an estimated total body length of 2.94 - 4.25 metres (m) for IPUW 353500 and 2.21$3.15 \mathrm{~m}$ for IGR 2818. This size in comparisons to modern Pristidae and Rhynchobatidae of similar post rostral lengths suggest a weight of $70-150 \mathrm{~kg}$. sclerorhynchoids. As such, some batoid groups were not included (e.g. torpedinoids, 717 platyrhinoids and myliobatoids). We ignore these groups in the analysis because no previous phylogenetic analysis has established a close relationship between them and sclerorhynchoids (Claeson et al., 2013; Underwood \& Claeson, 2017; Villalobos et al., 2019a). However, when interpreting the main features that distinguish $\uparrow$ Onchopristis and sclerorhynchoids, we include them to give a broader perspective (see, phylogenetic analysis section). The sawsharks were not included in the present analysis, because morphological features like the presence synarcual and antorbital cartilages suggest a clear batoid affiliation for $\uparrow$ Onchopristis. the selection of features focused on these structures to avoid uncertainties in the phylogenetic analysis, related to the extensive inclusion of missing characters (?) that will ultimately affect

727 the resolution of the analysis. Thus, the use of other anatomical features (e.g. pelvic and 728 pectoral girdles) was avoided. 
The topologies recovered by the present analyses suggest that a different taxonomic affiliation for $\uparrow$ Onchopristis and $\dagger I$ schyrhiza could be proposed. Both analyses place these genera previously associated with $†$ Sclerorhynchidae (Cappetta, 2012) in a monophyletic group separated from the reaming sclerorhynchoids with relatively good group support (TreeSearch: Fig. $18 \mathrm{~B}$, Cs (strict) $=81 \%$ and Cs (majority) $=91 \%$; TNT: Fig $18 \mathrm{~A}, \mathrm{Cs}=82$ ) (see, TNT log in supplementary material). However, while there is a strong phylogenetic support for accommodating †Onchopristis and †Ischyrhiza in a single family (i.e. $\dagger$ Ischyrhizidae Cope, 1875), we argue for the formation of the family $†$ Onchopristidae, as resurrecting Cope’s (1875) †Ischyrhizidae would be taxonomically risky because the genus with the most complete fossil record is †Onchopristis. Consequently, it is expected that both taxa would be differentiated if more complete material of $\uparrow$ Ischyrhiza turns up resulting in excluding $\dagger$ Onchopristis from the family it diagnoses. As such $\dagger$ Onchopristidae is diagnosed by the presence of the following characters: (proposed characterised by the following features: (1) a very peculiar rostral morphology with a thick lateral layer of porous cartilage on the sides of the rostral cartilages, where the enlarge denticle lateral series attach (Character $($ Char $)=4$, 1, Consistency index $(\mathrm{Ci})=1)$; (2) an external layer of "wood-like" cartilage in the centre of the rostrum $(\mathrm{Char}=2,1, \mathrm{Ci}=1$ and $\mathrm{Char}=3,1, \mathrm{Ci}=1) ;(3)$ the presence of large denticles in the body (also see, Sternes \& Shimada, 2019) $(\mathrm{Char}=18,1, \mathrm{Ci}=1) ;(4)$ the presence of smaller denticles with a round cap associated with the base of the rostral denticles (Char $=28,1, \mathrm{Ci}=$ 1); and (5) two series of enlarged denticles with acute cap associated with the latera regions of the rostrum and head (Char $6,1, \mathrm{Ci}=1)$; (6) a symmetric addition of rostral denticles with denticles of different sizes being periodically added (Char $=11,2, \mathrm{Ci}=1)$; and (7) rostral denticles with a cap of filled with orthodentine $(\mathrm{Char}=24,0, \mathrm{Ci}=1)$. This combination of characters is unique compared to other sclerorhynchoids and differentiates $†$ Onchopristidae from any other taxon tentatively assigned to it (†Schizorhiza and $\dagger I$ schyrhiza). Therefore, the 
similarities in rostral morphology similarities (e.g. wood-like mineralization and the presence of a lateral layer of porous cartilage on the sides of the rostrum) seems more likely to be a convergent development since the addition and replacement of their rostral denticles seems radically different (Character 11) and requires more complete material of $\dagger$ Ischyrhiza to evaluate the status of this character in more detail.

There are some other uncertainties concerning the taxonomic hierarchy of the ptychotrygonoids. Villalobos et al. (2019b) suggest a placement within the Sclerorhynchidae family, based on similarities in their tooth morphology with those of $\dagger$ Libanopristis (i.e. present transverse crests in the labial apron, see Cappetta, 1980b, text-fig 7 B; 2012, text-fig. $368 \mathrm{I}$, in present analysis character 17). However, the teeth of $\dagger$ Libanopristis present a more prominent cusp, and the labial apron is less ornamented than that of ptychotrygonoids. In $\uparrow$ Ptychotrygon there is a deep central interlocking depression. Cappetta (1980) also indicated a lingual depression for some teeth of $\dagger$ Libanopristis hiram, but there are no clear illustrations, and we were unable to determinate if he refers to the lingual profile of the cusp below the apex or a region on the lingual uvula. Considering the present results, where ptychotrygonoids form a monophyletic group in by the strict consensus of TreeSearch with relatively high support (Fig. $18 \mathrm{~B}, \mathrm{Cs}$ (strict) $=91 \%$ and $\mathrm{Cs}$ (majority) $=81 \%$ ), a similar arrangement to $\dagger$ Onchopristidae is proposed for the $\uparrow$ Ptychotrygon and $\uparrow$ Asflapristis clade resurrecting the family $†$ Ptychotrygonidae sensu Kriwet et al. (2009). The TNT majority rule tree and the clade support analysis corroborates this placement (Fig. 18 A $\mathrm{Cs}=31$ ). Members of

$774 \uparrow$ Sclerorhynchidae are differentiated form $†$ Ptychotrygonidae in the presence of enlarged denticle series associated with the rostrum (lateral and both ventral (lateral and central) series $(\mathrm{Char}=7, \mathrm{Ci}=1, \mathrm{Char}=8, \mathrm{Ci}=1)$ and the presence of highly ornamented teeth with transversal crests in members of $\uparrow$ Ptychotrygonidae, $(\mathrm{Char}=17,1, \mathrm{Ci}=1)$. 

phylogenetically. The same could be said for †Onchopristidae, as both clades form part different groups which shares no immediate ancestor with $\dagger$ Sclerorhynchidae. However, their taxonomic identification is needed, as it helps the definition of sclerorhynchoids, facilitates the approach for future studies, and improves the current understanding of the group. Furthermore, we believe that there is enough evidence to support the taxonomical differentiation of the two groups into two families.

According to the present analyses, the genera $\uparrow$ Schizorhiza and $\uparrow I s c h y r h i z a$ should be placed within the Sclerorhynchoidei. The presence of a thick lateral layer of cartilage on the sides and the external layer of "wood-like" cartilage in their rostrum suggests its classification within $†$ Onchopristidae. However, considering that no cranial remains are known for both genera and that no enlarge body denticles are known for $\uparrow$ Schizorhiza, and its highly specialised replacement pattern of the lateral series of rostral denticles, their phylogenetic relationships within Sclerorhynchoidei remain uncertain for the moment.

\section{TAXONOMIC IMPLICATIONS}

Following these results, three families are suggested within Sclerorhynchoidei ( $†$ Sclerorhynchidae, $\uparrow$ Onchopristidae and $\uparrow$ Ptychotrygonidae) based on the differences in their rostral cartilages and dental morphologies. Within this arrangement the family $\dagger$ Onchopristidae is proposed, leaving the taxonomic classification for $\uparrow$ Onchopristis numidus as follows. 
807 Diagnosis of $\dagger$ Onchopristidae: Sclerorhynchoid group with a very peculiar rostral morphology, that includes a thick lateral layer of porous cartilage on the sides of the rostral cartilages, where the enlarge denticle lateral series attach. Rostral centre and superficial ophthalmic nerve canals covered with an external layer of "wood-like". Two series of enlarged

811 denticles with acute cap associated with the lateral regions of the rostrum and head, of which

812 the lateral rostrum series shows smaller denticles with a round cap associated with their base.

813 Symmetric addition of rostral denticles with denticles of different sizes being periodically

814 added. Rostral denticles with a cap of filled with orthodentine. Large denticles are associated 815 with the body (also see, Sternes \& Shimada, 2019 for $\dagger$ Ischyrhiza).

\section{CONCLUSION}

Currently, two species are assigned to $\dagger$ Onchopristis: $\dagger$ O. numidus and $\dagger$ O. dunklei,

819 both of which seem to be restricted to the Early to 'mid' Cretaceous (Barremian-Cenomanian).

820 These two species possess remarkably similar oral tooth morphologies but are differentiated

821 by the internal structure of the enlarge rostral denticles. The rostral denticles of $\uparrow$ Onchopristis numidus have an orthodentine filled cap, with a smaller pulp cavity that extends into the denticle cap, whereas the rostral of $\dagger O$. dunklei presents a larger pulp cavity that extends well

824 into the denticles cap and a thin orthodentine layer (McNulty \& Slaughter, 1962, text-fig. 1c). The peculiar neurocranial and rostral anatomy of the $\uparrow$ Onchopristis remains described here, with their rectangular shape of the post-nasal region, a reduced post-orbital process, an anterior fenestra located at the base of the rostral cartilages, and the lack of foramina or cavities at the base of the rostral cartilages for the supra ophthalmic nerve, confirm previous hypotheses 
that include the placement of $\dagger$ Onchopristis within the Sclerorhynchoidei (Cappetta, 1987;

2006; 2012). However, previous genus affiliations to the family Sclerorhynchidae are doubtful and not supported here, as the rostral anatomy and the addition and arrangement of the enlarge

832 rostral denticle series are different from other members of the group (e.g. $\dagger$ Sclerorhynchus and $833 \dagger$ Libanopristis) and resembles that of $\dagger$ Ischyrhiza. Following the phylogenetic analysis, three monophyletic clades are recognised within Sclerorhynchoidei, which based on their differences in their rostral cartilages and dental morphologies are interpreted as families by the present study: $\uparrow$ Sclerorhynchidae, $†$ Onchopristidae and $\uparrow$ Ptychotrygonidae. Recognising a new group within the Sclerorhynchoidei, the family †Onchopristidae that includes a single the genus $\dagger$ Onchopristis.

\section{ACKNOWLEDGEMENTS}

841 We thank the NHMUK for the use of their facilities and equipment for the preparation of the specimens, and M. Graham for the training in the use of the equipment. We also thank Emma Bernard at the NHMUK for her help with access to and curation of fossil specimens. We also thank the preparation team at the Institute of Palaeontological Research at the University of Vienna for their curation work. We are particularly indebted to Brahim Tahiri, Moha Ouhouiss, Hamad and Moha Segaoui who let us purchase the specimens at very reasonable prices and guide us through the localities. We also thank Bernard Hogrel kindly providing the Rennes specimen and Damien Gendry for the photographs of the Rennes specimen. We also want to thank Tyler Greenfield for his observation regarding the taxonomic classification proposed

850 here. Thanks to the CONACYT for the PhD Scholarship. Finally, we want to thank Todd Cook, an anonymous reviewer and editor for their comments and guidance on the early draft of this paper. 
Aschliman NC, Claeson KM, McEachran JD. 2012. Phylogeny of Batoidea. In: Carrier JC, Musick JA, Heithaus MR, eds. Biology of Sharks and Their Relatives. Florida: CRC Press, Boca Raton, 57-95.

Belvedere M, Jalil NE, Breda A, Gattolin G, Bourget H, Khaldoune F, Dyke GJ. 2013. Vertebrate footprints from the Kem Kem Beds (Morocco): A novel ichnological approach to faunal reconstruction, Palaeogeography, Palaeoclimatology, Palaeoecology 383: 52-58.

Bernardez E. 2002. Los dientes de seláceos del Cretácico de la Depresión Central Asturiana. Unpublished D. Phil. Thesis, University of Oviedo.

Brazeau, MD. 2011. Problematic character coding methods in morphology and their effects. Biological Journal of the Linnean Society 104: 489-498.

Brazeau MD, Guillerme T, Smith MR. 2019. An algorithm for Morphological Phylogenetic Analysis with Inapplicable Data, Systematic Biology 68: 619-631.

Cappetta H. 1980. Les sélaciens du Crétacé supérieur du Liban. II. Batoïdes, Palaeontographica, Abteilung A 168: 149-229.

Cappetta H. 1987. Chondrichthyes II. Mesozoic and Cenozoic Elasmobranchii. Handbook of Paleoichthyology, Volume 3B. Gustav Fisher Verlag, Stuttgart.

Cappetta H. 2006. Fossilium Catalogus, I: Animalia. Backhuys Publishers, Leiden, Netherlands.

Cappetta H. 2012. Chondrichthyes: Mesozoic and Cenozoic Elasmobrachii: Teeth, Volume 3E. Gustav Fischer Verlag. München.

Cavin L, Forey LP. 2004. New mawsoniid coelacanth (Sarcopterygii: Actinistia) remains from the Cretaceous of the Kem Kem Beds, Southern Morocco. In Arriatia G, Tintori A, eds. Mesozoic fishes Systematics Paleoenvironments and Biodiversity, Volume 3. München: Verlag Dr. Friedrich Pfeil, 101-109. 

Buffetaut E, Dyke G. 2010. Vertebrate assemblages from the Early-Late Cretaceous of southeastern Morocco: an overview, Journal of African Earth Sciences 57: 391-412.

Claeson KM, Underwood CJ, Ward DJ. 2013. †Tingitanius tenuimandibulus, a new platyrhinid batoid from the Turonian (Cretaceous) of Morocco and the Cretaceous radiation of the Platyrhinidae, Journal of Vertebrate Palaeontology 33:1019-1036.

Cope ED, 1875. The vertebrata of the Cretaceous formations of the west: Report of the United States Geological Survey of Territories, 2: 1-303.

Cuny G, Ouaja M, Srarff D, Schmitz L, Buffetaut E. 2004. Fossil sharks from the Early Cretaceous of Tunisia. Revue de Paléobiologie 9: 127-142.

De Lapparent AF, Gorce F. 1960. The dinosaurs of the "Continental Intercalaire" of the central Sahara. Memoirs of the Geological Society of France 39: 1-57.

Douady CJ, Dosay M, Shivji MS, Stanhope MJ. 2003. Molecular phylogenetic evidence refuting the hypothesis of Batoidea (rays and skates) as derived sharks. Molecular phylogenetics and evolution 26: 215-221.

Dutheil BD. 1999. An overview of the freshwater fish fauna from the Kem Kem Beds (Late Cretaceous: Cenomanian) of Southeastern Morocco. In: Arratia G, Schultze HP, eds. Mesozoic Fishes Systematics and Fossil Record, Volume 2. München: Verlag Dr. Friedrich Pfeil, 553-563.

Ettachfini EM, Andreu B. 2004. Le cénomanien et le turonien de la plateforme préafricaine du Maroc. Cretaceous Research 25: 277-302.

Fricke R, Eschmeyer WN, van der Laan R. 2020. Eschmeyer's catalog of fishes: genera, species, references at: http://researcharchive.calacademy.org/research/ichthyology/ catalog/fishcatmain.asp, accessed 9 June 2020. 
Goloboff PA, Farris J, Nixon K. 2013. TNT: Tree Analysis Using New Technology. Updated

904 at: http:// www.lillo.org.ar/phylogeny/tnt/, accessed 12 January 2019.

905

906

907

908

909

910

911

912

913

914

915

916

917

918

919

920

921

922

923

924

925

926

927

Haug E. 1905. Paléontologie. Documents scientifiques de la Mission saharienne (Mission Foureau-Lamy). Publication de la Société de Géographie 1905: 751-832.

Huxley TH. 1880. On the application of the laws of evolution to the arrangement of the Vertebrata and more particularly of the Mammalia. Proceedings of the Zoological Society of London. Zoological Society of London 1880: 649-662 pp.

\section{Ibrahim N, Sereno PC, Varricchio DJ, Martill DM, Dutheil DB, Unwin DM, Baidder L,} Larsson HCE, Zouhri S, Kaoukaya A. 2020. Geology and paleontology of the Upper Cretaceous Kem Kem Group of eastern Morocco. ZooKeys 928: 1-216. https://doi.org/10.3897/zookeys.928.47517

Keyes IW. 1977. Records of the northern hemisphere Cretaceous Sawfish genus Onchopristis (order Batoidea) from New Zealand. New Zealand Journal of Geology and Geophysics 20:263-272.

Kilian C. 1931. Des principaux complexes continentaux du Sahara. Comptes Rendus Sommaires de la Société Géologique de France 9: 109-111.

Kirkland J, Aguillón-Martínez, M. 2002. Schizorhiza: a unique sawfish paradigm from the Difunta group, Coahuila, México. Revista Mexicana de Ciencias Geológicas 19(1):1624.

Kriwet J. 1999. Neoselachier (Pisces, Elasmobranchii) aus der Unterkreide (unteres Barremium) von Galve und Alcaine (Spanien, Provinz Teruel). Paleo Ichthyologica 9: $113-142$.

Kriwet, J. 2004. The systematic position of the Cretaceous sclerorhynchid sawfishes (Elasmobranchii, Pristiorajea). In: Arratia G, Schultze HP, eds. Mesozoic Fishes Systematics and Fossil Record, Volume 3. München: Verlag Dr. Friedrich Pfeil, 57-73. 
Kriwet J, Kussius K. 2001. Paleobiology and paleobiogeography of sclerorhynchid sawfishes (Chondrichthyes Batomorphii). Revista Española de Paleontología 16: 35-46.

Kriwet J, Nunn EV, Klug S. 2009. Neoselachians (Chondrichthyes, Elasmobranchii) from the Lower and lower Upper Cretaceous of north-eastern Spain. Zoological Journal of the Linnean Society 155: 316-347.

Läng E, Boudad L, Maio L, Samankassou E, Tabouelle J, Tong H, Cavin L. 2013. Unbalanced food web in a Late Cretaceous dinosaur assemblage. Palaeogeography, Palaeoclimatology, Palaeoecology 381: 26-32.

Leidy J. 1856. Notice of some remains of fishes discovered by Dr. John E. Evans. Proceedings of the Academy of Natural Science of Philadelphia 8: 256-257.

Maddison WP, Maddison DR. 2018. Mesquite: A Modular System for Evolutionary Analysis. Version 3.51 Available at http://mesquiteproject.org.

Mannion PD, Barrett PM. 2013. Additions to the sauropod dinosaur fauna of the Cenomanian

(early Late Cretaceous) Kem Kem Beds of Morocco: Palaeobiogeographical

Martill DM, Ibrahim N. 2012. Aberrant rostral teeth of the sawfish Onchopristis numidus from the Kem Kem Beds (? early late cretaceous) of Morocco and a reappraisal of Onchopristis in New Zealand. Journal of African Earth Sciences 64: 71-76.

McEachran JD, Aschliman N. 2004. Phylogeny of Batoidea. In: Carrier JC, Musick JA, and Heithaus MR, eds. Biology of sharks and their relatives. Florida: CRC Press, Boca Raton 79-113.

McNulty CL, Slaughter BH. 1962. A new sawfish from the Woodbine Formation 
Miller W. 1974. Observations on the Developing Rostrum and Rostral Teeth of Sawfish: Pristis perotteti and P. cuspidatus. Copeia 1974: 311-318.

Morgan DL, Whitty JM, Phillips NM, Thorburn DC, Chaplin JA, McAuley R. 2011. North-western Australia as a hotspot for endangered Elasmobranchs with particular reference to sawfishes and the Northern river Shark. Journal of the Royal Society of Western Australia 94: 345-358.

Miyake T, McEachran JD, Walton PJ, Hall BK. 1992. Development and morphology of rostral cartilages in batoid fishes (Chondrichthyes: Batoidea), with comments on homology within vertebrates. Biological Journal of the Linnean Society 3: 259-298.

Naylor GJ, Caira JN, Jensen K, Rosana KA, Straube N, Lakner C. 2012. Elasmobranch phylogeny: A mitochondrial estimate based on 595 species. In: Carrier JC, Musick JA, Heithaus MR, eds. Biology of Sharks and Their Relatives. Florida: CRC Press, Boca Raton, 31-56

Néraudeau D, Vullo R, Gomez B, Vincent P, Videt B. 2005. Stratigraphie et paléontologie (plantes, vertébrés) de la série paralique Albien terminal-Cénomanien basal de TonnayCharente (Charente-Maritime, France). Compte Rendus Palevol 4: 79-93.

Pereira AA, Mdeiros MA. 2008. A new Sclerorhynchiform (Elasmobranchii) from the middle Cretaceous of Brazil. Revista Brasileira de Paleontologia 11: 207-212.

Rage JD, Dutheil DB. 2008. Amphibians and squamates from the Cretaceous (Cenomanian) of Morocco. A preliminary study, with description of a new genus of pipid frog. Palaeontographica Abteilung A 285: 1-22.

Sereno PC, Dutheil DB, Iarochène M, Larsson HCE, Lyon GH, Magwene PM, Sidor CA, Varricchio DJ, Wilson JA. 1996. Predatory Dinosaurs from the Sahara and Late Cretaceous Faunal Differentiation. Science 272: 986-991. 
Slaughter BH, Steiner M. 1968. Notes on Rostral Teeth of Ganopristine Sawfishes, with Special Reference to Texas Material. Journal of Paleontology 42: 233-239.

Slaughter BH, Thurmond JT. 1974. A Lower Cenomanian (Cretaceous) ichthyofauna from the Bahariya Formation of Egypt. Annals of the Geological Society, Egypt 4: 25-40.

Smith MM, Riley A, Fraser GJ, Underwood CJ, Welten M, Kriwet J, Pfaff C, Johanson

Z. 2015. Early development of rostrum saw-teeth in a fossil ray tests classical theory 982 of the evolution of vertebrate dentitions. Proceedings of the Royal Society B: Biological Sciences 282: 20151628.

Sternes PC, Shimada K. 2019. Paleobiology of the Late Cretaceous sclerorhynchid sawfish, 985 Ischyrhiza mira (Elasmobranchii: Rajiformes), from North America based on new anatomical data. Historical Biology 31: 1323-1340.

Stromer E. 1917. Ergebnisse der Forschungsreisen Prof. E. Stromers in den Wiisten Agyptens. 11. Wirbeltier-Reste der Baharije-Stufe (Unterstes Cenoman). 4: Die Sage des Pristiden Onchopristis. Abhandlungen de Bayerischen Akademie der Wissenchaften, Mathematish-naturwissenschaftliche Abteilung 28: 1-31 pp.

Stromer E. 1925. Ergebnisse der Forschungsreisen Prof. E. Stromers in den Wiisten Agyptens. 11. Wirbeltier-Reste der Baharije-Stufe (Unterstes Cenoman). 8. Ein Skelettrest des Pristiden Onchopristis numidus Haug sp. Abhandlungen de Bayerischen Akademie der Wissenchaften, Mathematish-naturwissenschaftliche Abteilung 30: 1-22.

Stromer E. 1927. Ergebnisse der Forschungsreisen Prof. E. Stromers in den Wiisten Agyptens. 11. Wirbeltier-Reste der Baharije-Stufe (Unterstes Cenoman). 9. Die Plagiostomen mit einem Anhangiiber kano und mesozoische Riickenflossenstacheln von Elasmobranchiern. Abhandlungen de Bayerischen Akademie der Wissenchaften, Mathematish-naturwissenschaftliche Abteilung 31: 1-67. 
Thurmond JT. 1971. Cartilaginous fishes of the Trinity Group and related rocks (lower Cretaceous) of north central Texas. Southeastern Geology 13: 207-227.

Underwood CJ, Claeson K. 2017. The Late Jurassic ray Kimmerobatis etchesi gen. et sp. nov. and the Jurassic radiation of the Batoidea. Proceedings of the Geologists Association 30: $345-354$

Underwood CJ, Smith MM, Johanson Z. 2016. Sclerorhynchus atavus and the convergent evolution of rostrum-bearing chondrichthyans. Geological Society, London, Special Publications 430: 129-136.

Underwood CJ, Ward DJ, King C, Antar SM, Zalmout IS, Gingerich PD. 2011. Shark and ray faunas in the Middle and Late Eocene of the Fayum Area, Egypt. Proceedings of the Geologists' Association 122: 47-66.

Villalobos-Segura E, Underwood CJ, Ward DJ, Claeson KM. 2019a. The first threedimensional fossils of Cretaceous sclerorhynchid sawfish: Asflapristis cristadentis gen. et sp. nov., and implications for the phylogenetic relations of the Sclerorhynchoidei (Chondrichthyes). Journal of Systematic Palaeontology 17: 1847-1870

Villalobos-Segura E, Underwood CJ, Ward DJ. 2019b. The first skeletal record of the Cretaceous enigmatic sawfish genus Ptychotrygon (Chondrichthyes: Batoidea) from the Turonian (Cretaceous) of Morocco. Papers in Palaeontology 2019: 1-24

Vullo R, Néraudeau D, Videt B. 2003. Un faciès de type falun dans le Cénomanien basal de Charente-Maritime (France). Annales de Paléontologie 89: 171-189.

Welten M, Smith MM, Underwood CJ, Johanson Z. 2015. Evolutionary origins and development of saw-teeth on the sawfish and saw shark rostrum (Elasmobranchii; Chondrichthyes). Royal Society Open Science 2: 1-19.

Welton BJ, Farish RF. 1993. The collector's guide to the fossil sharks and rays from the Cretaceous of Texas. USA: Before Time. 
1025 Werner C. 1989. Die Elasmobranchier-Fauna des Gebel Dist Member der Bahariya Formation (Obercenoman) der Oase Bahariya, Agypten. Palaeo Ichthyologica 5: 1-112.

1027 Whitty JM, Phillips NM, Thorburn DC, Simpfendorfer CA, Field I, Peverell SC, Morgan DL. 2014. Utility of rostra in the identification of Australian sawfishes (Chondrichthyes: Pristidae). Aquatic Conservation: Marine and Freshwater

1030 Ecosystems 24: 791-804.

1031

1032

1033

1034

1035

1036

1037

1038

1039

1040

1041

1042

1043

1044 